\title{
LAS CALLES DE CORDOBA EN EL SIGLO XV: CONDICIONES DE CIRCULACION E HIGIENE
}

Ricardo Córdoba de la Llave

Universidad de Córdoba

Desde el siglo XIII el fenómeno urbano se extiende y consolida por toda Europa. A una época caracterizada por el absoluto predominio de las aldeas y de los campos va a suceder otra, de la que aun somos deudores, en que las ciudades se convierten en las protagonistas de la vida humana en Europa Occidental. $Y$ aunque hasta el presente siglo la población residente en ciudades no ha superado a la rural (en pleno siglo XVIII un 80 por 100 de la población europea continuaba viviendo en el campo), lo cierto es que las ciudades cobraron en el curso de los siglos XIV y XV una importancia que no ha dejado de acrecentarse desde entonces.

En consonancia con el crecimiento demográfico experimentado por las villas, surgieron durante la Baja Edad Media una amplia serie de problemas urbanísticos a los que las autoridades municipales de la época hubieron de hacer frente en un intento por darles solución. $Y$ aunque esa solución rara vez se consiguió (de hecho, una buena parte de los problemas de infraestructura urbana entonces planteados se mantienen vigentes en nuestros días), la actividad desplegada por los gobiernos municipales dió lugar a la emisión de una gran cantidad de disposiciones que, bajo la forma de ordenanzas o acuerdos capitulares, se conservan en los principales archivos municipales hispanos. A través de ellas es posible examinar cuáles fueron los principales problemas a los que el urbanismo medieval hubo de enfrentarse y cuáles las principales medidas que se tomaron para intentar paliarlos.

En Córdoba, esos documentos se tornan especialmente abundantes a partir del reinado de los Reyes Católicos y la actividad desplegada por el municipio en este sentido ha quedado registrada en los libros de actas capitulares del concejo, de los que nos quedan para el siglo $X V$ tan solo los correspondientes a 1479, 1493 y 1495-99. Con la información contenida en esos libros y en algunas ordenanzas de carácter urbanístico hemos estudiado el caso del trazado viario de Córdoba, 
amenazado por unos problemas prácticamente idénticos a los que se dieron en casi todas las ciudades europeas y castellanas coetáneas, combatidos a su vez mediante la puesta en práctica de una legislación municipal igualmente coincidente. Así tendremos ocasión de ponerlo de manifiesto a lo largo de las páginas siguientes mediante el cotejo de las disposiciones emitidas en Córdoba con las promulgadas en diversas ciudades británicas, francesas y peninsulares.

\section{EL TRAZADO VIARIO Y LOS PROBLEMAS DE CIRCULACIÓN}

La calle constituye en toda ciudad el principal elemento del paisaje urbano, puesto que en ella se desarrolla la vida de sus habitantes desde todos los puntos de vista. Como en la mayor parte de los centros urbanos de época bajomedieval, el trazado viario de Córdoba se caracterizaba por su irregularidad, resultado de un crecimiento llevado a cabo sin plan regulador previo, así como por su brevedad y estrechez.

Lo primero que llama la atención es el carácter extremadamente angosto de muchas vías. Es verdad que la anchura de una calle es un elemento relativo, puesto que mientras en una aldea una calzada de tres o cuatro metros puede resultar suficiente para el tráfico que se desarrolla en ella, en una gran aglomeración, particularmente en zonas de mercado o intensa actividad laboral, calles de ocho o diez metros apenas bastan para contener la circulación en su interior. En todo caso, las grandes arterias, las calles que podríamos denominar "maestras", fueron muy escasas; medían entre ocho y diez metros de ancho, se trataba por lo general de las calles de acceso que se introducían en la ciudad siguiendo las principales rutas que arrivaban a ella y presentaban un carácter excepcional subrayado siempre por los documentos que a ellas aluden.

Las calles medievales comunes solían tener una anchura entre dos y cinco metros y presentar un perfil sinuoso que añadía dificultades a su propia angostura física: callejas con múltiples quiebros, rincones o extremos cerrados eran frecuentes en la época, más aun en ciudades como Córdoba y Sevilla, en buena parte herederas de un urbanismo islámico que acentuó ese carácter del paisaje urbano.

$Y$ junto a ellas, eran frecuentes los adarves, barreras y callejas sin salida, que en ciertos barrios de los que son buena muestra las juderías de Córdoba y Sevilla llegaron a constituir un microorganismo de circulación, un complejo laberinto de vías peatonales, a veces públicas, a veces privadas (en muchas ocasiones los vecinos cerraban estas calles en su propio beneficio o añadiendo parte del espacio público a sus viviendas), que raramente excedían el metro o los dos metros de anchura. Estas fueron consideradas en la época cada vez como más siniestras e incómodas y muchas fueron desapareciendo al quedar incorporadas a las viviendas próximas o ser ensanchadas mediante reformas. 
A la estrechez de las calles se unían las dificultades representadas por los elementos de fachada que se adentraban en su interior, restando espacio a las vías de comunicación, y por la costumbre, muy extendida en la época, de enlazar las viviendas de fachadas opuestas mediante una habitación construida en su planta alta y que cubría la calle por arriba, los famosos soberados que dieron lugar a las denominadas en Córdoba "encubiertas", calles oscuras en las que apenas entraba el sol debido a la sucesiva colocación de soberados que ocasionaban los correspondientes problemas de altura e higiene.

El caso inverso a este era el representado por las calles con soportales, muy usadas también en la ciudad bajomedieval, que daban mayor amplitud al espacio público y permitían un tránsito más holgado de personas y animales; pero como quiera que dichos soportales eran habitualmente usados por vecinos y menestrales para tener bajo su amparo mesas, tableros, poyos y otros elementos de trabajo o uso cotidiano, el único desahogo cierto del trazado viario estaba constituido por las plazas, escenario al que se abrían muchas de las casas principales, palacios e iglesias y que no debemos entender como un centro amplio del que surge una estructura viaria más o menos radial (como hoy las entendemos), sino más bien como simples ensanches de calles o lugares en los que al confluir dos o más vías se originaba un espacio más ancho.

A todos estos problemas derivados de la misma naturaleza del trazado viario medieval se unían aquéllos provocados por el tráfico urbano, la actividad laboral de los distintos oficios que trabajaban en las calles y las propias costumbres y hábitos de una sociedad cuya noción del espacio público en relación con el privado distaba mucho de estar bien definida.

En todas las ciudades del Occidente europeo son frecuentes, a fines de la Edad Media, las quejas y denuncias presentadas, ya por parte del vecindario afectado, ya por parte de los poderes municipales, sobre las dificultades de circulación por las calles, los estorbos colocados enmedio de ellas, los abusos cometidos por los particulares en el uso de los espacios comunes o la violación de las normas urbanísticas más elementales sobre disposición de fachadas, aceras y elementos arquitectónicos. Tales problemas dieron lugar a una amplia documentación que refleja, en todos los casos, la constante preocupación de los cabildos por mantener las calles en el mejor estado circulatorio posible y el constante incumplimiento de las disposiciones que, a tal efecto, dictaron; desobediencia ocasionada más por la existencia de unas costumbres y tradiciones difíciles de desarraigar que por la falta de espiritu cívico o por la misma dejadez de los vecinos.

Entre los problemas que de forma más habitual se presentaron destaca el del tráfico de carretas y bestias por las calles, especialmente si éstas eran estrechas y concurridas. Sabemos que, en 1297, un edicto del monarca Eduardo I prohibió su circulación por el londinense barrio de San Martin después de una determinada hora del día, de igual modo que una 
reglamentación de los primeros años del siglo XIV vetó la entrada de carros en el centro urbano de Florencia en las que hoy llamaríamos "horas punta". (1)

Estas disposiciones se desarrollaron de manera especial en el curso de los siglos XV y XVI y afectaron a muchas ciudades y villas hispanas. En Zaragoza, los capitulares denunciaron en 1471 cómo por ciertas calles las carretas apenas cabían, rozaban en las paredes, tiraban los bancos, aplastaban los tablados y con su trepidación removían los muros, por lo que algunas casas se caían y no pocas veces resultaban atropelladas personas; en la ciudad de Burgos en 1429, acabó por prohibirse la circulación de carretas por determinadas zonas bajo amenaza de pérdida de los vehículos; y en la pequeña villa de Tobarra las disposiciones emitidas al respecto, ya en pleno siglo XVI, sorprenden por su detallismo: "por quanto en esta villa han acaecido muchos peligros a causa de los carreteros no traer el recado que conviene en sus mulas e carros, ansi entrando en la dicha villa como saliendo, [...] el carretero que entrare en esta dicha villa sin traer sus mulas del cabestro o en los palillos - llevándolas o trayéndolas de la guía de los ramales o a caballeros en ellas, que caiga en pena de medio real para el almotacén por cada vez que lo tomare, e demás pague el daño que hiciere". (2)

Otro tipo de quejas que aparecen en gran abundancia son las realizadas con motivo de las muchas materias que los vecinos acumulaban o dejaban abandonadas enmedio de la calle, obstaculizando la circulación e impidiendo el normal desarrollo de las actividades cotidianas. Resultaba usual que los particulares amontonasen en la vía pública los pertrechos de madera, piedra, arena y otros materiales usados para hacer obra en sus viviendas, así como los escombros resultantes de las mismas, por más que las ordenanzas de alarifes trataran de impedirlo cuando disponían "que los alarifes hagan quitar de la calle real el pertrecho de madera e piedra que traen muchos para las lauores de sus casas, pues muchas ueces ocurre que traen en sus carretas e la dejan alli mucho tienpo"; o cuando mandaban "que pague doze mrs. quien enbargare las calles con madera, piedra, ramas o en otra manera semeiante, e quien la calle del rey enbargue peche la pena de doze mrs. por cada uez que lo fiziere a los alarifes". ${ }^{(3)}$

En otras ocasiones las calles se vieron ocupadas por escombros procedentes, bien de una obra más o menos lejana, bien de viejas paredes y muros que se habían caído. Las ordenanzas contemplaron este problema al indicar que "ocurre muchas vezes que se cae la pared o casa en la calle real e enbarga la calle atajando el paso de la gente, dejándola allí su dueño mucho tiempo; los alarifes deuen mandarle retirarla e darle plazo so pena de quatroçientos mrs.". Y el cabildo se vió obligado a ejercer una vigilancia continuada sobre estas cuestiones como demuestra el encargo dado a un jurado para "ver una pared que está acostada en la calle de Luis Méndez", o el efectuado a dos veinticuatros para que, junto con el obrero del cabildo y los alarifes, viesen "un adarue que está frente a 
la iglesia de la Magdalena que diz que se quiere caer e lo que fuere menester para ello se repare". ${ }^{(4)}$ En todo caso, aún hoy se siguen formando basureros y los habitantes de una ciudad continúan arrojando escombros en los solares vacíos del casco urbano; no puede sorprender, por lo tanto, que hace quinientos años los vecinos de Córdoba o de cualquier otra ciudad no siempre se tomasen el trabajo de llevar los escombros fuera de la ciudad, ni se dieran prisa en retirar los procedentes de edificios arruinados. De hecho, este problema (como la mayor parte de cuantos aquí tratamos) ha seguido persistiendo en siglos posteriores, como se detecta, por ejemplo, en la Sevilla del Seiscientos, sin que hasta el presente siglo pudieran hallarse soluciones adecuadas. ${ }^{(5)}$

De cualquier modo, y al lado de estos problemas viarios que podemos calificar de insolubles, existían algunos otros que respondían más estrictamente a las costumbres de una sociedad poco sensibilizada por el decoro urbano, y que hubieran podido ser evitados si el egoísmo de los particulares no hubiera hecho privar en cada momento sus propios intereses sobre los del conjunto urbanístico. Quizá el mayor obstáculo para la fluidez de la circulación estaba representado por la colocación de elementos de fachada que se adentraban en el espacio público de la calle impidiendo el paso franco de personas y vehículos.

Los bancos y los poyos constituyen dos buenos ejemplos. Se trataba de construcciones adosadas a la pared externa de la casa y usadas por cada vecino para su trabajo o solaz. En algunas ciudades, las ordenanzas locales fijaban las dimensiones máximas que en longitud, anchura y altura podían tener estos elementos, según las características de la calle donde fueran ubicados; así ocurre en Zaragoza, donde la longitud permitida solía ser igual a la de la fachada de la casa, mientras la anchura oscilaba entre los $50 \mathrm{cms}$. y un metro, y el criterio utilizado para fijar la altura era la medida de los bancos o poyos circundantes; mientras que las ordenanzas de Córdoba prohibían hacer los bancos de manera que resultasen molestos u ocupasen excesivo espacio de calle, indicando que no debía ser hecho "poyo en calle ni en calleja que enbargue mucho las calles e estorbe el trato e paso de las gentes". ${ }^{(6)}$ Pero como quiera que dicha regulación no existió en todas las ciudades o no siempre fue respetada, los poyos y bancos solían muchas veces adentrarse considerablemente en la calle, obstaculizando el paso de personas, animales y carros y restando anchura a vías ya de por sí suficientemente angostas, de forma que no se dudó en retirarlos cuando el bien público así lo exigía. El derribo de poyos y bancos para ampliar una calle no resultó por ello extraño y así ocurrió con algunos de los existentes en Segovia a fines del siglo $\mathrm{XV}$ y con los situados en las calles más céntricas de la ciudad al ser empedradas en 1493, fecha en la que el cabildo ordenaba "que desde la puerta del Rincón fasta la puerta de la Pescadería como ua por los escriuanos públicos e cal de la Feria, se quiten e derriben los poyos e calçadas que ouieren porque se tyenen que enpedrar, e desde la puerta de Baeça la calle que ua por el Potro e Pescadería fasta Santa 
María, otrosí se derriben los poyos e calçadas que ouiere en un plazo de seys días". (7)

Esta circunstancia no indica, sin embargo, que tales elementos fueran considerados peligrosos o perjudiciales ni se intentaran suprimir, salvo en casos aislados y por razones muy concretas. Lo habitual es que se continuaran construyendo y de ello tenemos abundantes ejemplos; en 1496 los cofrades del hospital de la plaza de la Corredera solicitaron permiso al municipio para hacer un poyo junto a dicho hospital y en 1498 el cabildo mandó librar de los propios del concejo los maravedís necesarios "para el poyo que se faze en la Corredera para el juzgado del alcalde de las dehesas"; además, diversos oficios o vendedores ejercían su trabajo precisamente sobre estas construcciones adosadas al exterior de los edificios, caso de un herrador que trabajaba a la puerta del mesón del Potro. ${ }^{(8)}$ Aunque los alarifes y otros oficiales eran encargados por el cabildo de ver el lugar donde el poyo o banco había de ser construido y autorizar o no su edificación, lo cierto es que en bastantes ocasiones no se vieron los perjuicios ocasionados por tales elementos hasta que no fue demasiado tarde para retirarlos, o fueron consentidos aún cuando se evidenciara que su colocación en determinado lugar dificultaba la circulación y obstaculizaba el normal desarrollo de las actividades.

Algo similar sucedía con los saledizos y balcones que eran, por así decirlo, el equivalente en altura de lo que poyos y bancos representaban en superficie, es decir, elementos de fachada que ampliaban la superficie útil de las viviendas en detrimento del espacio urbano. Tres eran los tipos más comunes de saledizo: los tejadillos colocados sobre puertas y ventanas a fin de protegerlas de la lluvia o resguardar la intimidad del hogar de las miradas de los vecinos más próximos; los ajimeces y balcones colocados a media fachada para asomarse al exterior o para soportar la ampliación de las habitaciones superiores sobre la línea de fachada de la planta baja (mediante colocación de paredes apoyadas en canes o trozos de viga que sobresalian respecto de ésta); y los aleros de los tejados.

Como hemos visto en el caso de los bancos, los reglamentos para su construcción eran muy estrictos. En Zaragoza había que hacerlos alineados con los de las casas contiguas, de un saliente determinado y de tal altura que pudiera pasar bajo ellos un hombre a caballo; en Córdoba, quedaban regulados por las ordenanzas de alarifes cuando indicaban que "nadie debe sacar el ala de su tejado más de ladrillo e medio en la mayor salida, que se entiende dos palmos" --es decir, poco más de $40 \mathrm{cms}$.--, que "qualquiera que fiziere ajimez o balcón saledizo en el aire sobre la calle no lo saque más del ancho del quarto de la calle, porque si el otro vezino quisiere fazer en frente otro tanto quede en la calle del claro con el çielo la mitad e la otra mitad para los ajimezes, uno de una parte e otro de otra" y que si algún vecino hiciera un saledizo "hágalo alto que no estorbe el paso de los caualleros que fueran caualgando e no lo saque más en anchura si fuere calle angosta del quarto de la calle porque pueda el de la 
otra parte fazer otro tanto e quede en la calle por arriba entre los tejados de hueco la mitad". ${ }^{(9)}$

Pese a esta reglamentación tan minuciosa, los abusos debieron ser muchos y muchos también los problemas planteados por los saledizos, incluso por los edificados dentro del "marco legal", sobre todo en calles de gran estrechez y mal iluminadas. Ello explicaría que en casi todas las ciudades peninsulares se denote, a fines del siglo XV, un acusado empeño por eliminar estas construcciones. En Segovia se ordenó no edificar más saledizos y retirar algunos de los existentes en 1497; del mismo modo que se procedió en Plasencia en 1511 al ordenar su cabildo no reparar ni edificar más balcones ni saledizos por la estrechez que los mismos ocasionaban en las calles; pero quizá las disposiciones más expresivas las hallamos en Valladolid, donde en 1496 se ordenaba al corregidor no permitir edificar saledizos, corredores o balcones por las delanteras de las casas "que salen por gran trecho ocupando toda o la mayor parte de la calle" y se justificaba esta medida por razones de higiene y salubridad, puesto que al no poder entrar en ellas claridad, aire ni sol "de continuo están muy umedas e lodosas e suzias".(10) Aunque en Córdoba no conocemos disposición general alguna a este respecto, el cabildo ordenó en repetidas ocasiones la desaparición de algún saledizo, por ejemplo en 1499 cuando dispuso que "para ennobleçer la calle de la puerta del Hierro se derriben todos los tejadillos que están en la dicha calle a la mano derecha, desde el canto donde está Leonardo fasta el cabo donde uenden los turrones, porque queden desenbargadas las calles" y que "los tejadillos que hay a las puertas desde la puerta del Rincón fasta el Aduana e los Marmoleios que los quiten sus dueños o si no la cibdad los fará quitar a costa de sus dueños fasta San Andrés". (11)

De naturaleza similar eran los problemas presentados por los soberados o cámaras que enlazaban unas casas con otras sobre la calle por su planta superior. La proliferación de los mismos en el siglo XV dió lugar, como ya hemos indicado, a las calles denominadas encubjertas, parcial o totalmente cerradas por arriba con estas habitaciones $\mathrm{y}$, por lo tanto, muy oscuras, donde apenas penetraba la luz solar, y generalmente muy bajas, de forma que en ocasiones resultaba incluso difícil el paso de una persona andando. El poder municipal trató de obviar, siquiera parcialmente, los inconvenientes por ellas representados regulando la altura de esos soberados, para lo cual las ordenanzas de Córdoba disponian "que los soberados que atrauiesan las calles no lo puedan fazer sin licençia de la çibdad e si lo fizieren que lo fagan de altura que pueda pasar un cauallero con sus armas de manera que no le estorbe e si lo fizieran más bajo e estorbase el paso e seruiçio de la calle que el alarife lo faga derribar", y en ello coincidían con lo que parece haber sido una norma general de la época, puesto que ordenanzas de Sevilla prohibian igualmente construirlos a menor altura; en Burgos, el concejo dió licencia para hacer uno de estos pasadizos en 1430 con la obligación de dejar paso a un "ome de mula"; y en Zaragoza mandamientos capitulares de los 
años 1468 y 1472 recordaban también que los pasos elevados debían ser lo suficientemente altos como para permitir el paso de un hombre a caballo. ${ }^{(12)}$

Otro de los factores que más incidieron en las dificultades circulatorias fue el de la actividad profesional del mundo urbano. Las labores comerciales y artesanales desarrolladas en las calles determinaban, en gran medida, el paisaje urbano de la época y hacian de dichas vías, tomando una definición dada por J. Milley a propósito de París, "a la vez un pasaje, un taller, una oficina donde se tratan asuntos y un mercado permanente". ${ }^{(13)}$ A lo largo de toda la jornada, vendedores y artesanos trabajaban a vista de quienes circulaban, a veces tras un mostrador o botica, a veces en plena calle con sus instrumentos y puestos. Los reglamentos corporativos al uso así lo exigían para facilitar el control de las operaciones técnicas y permitir a los eventuales clientes contrastar la calidad de los productos. Los estatutos de los sastres parisinos, reseñados por Etienne Boileau en su Libro de los Oficios, que fue redactado durante el reinado de San Luis, precisaban que el maestro no podía hacer su trabajo "más que a la vista del pueblo".(14)

Gracias a ello, las tiendas y talleres adquirieron hacia la calle una disposición particular y se vieron rodeadas de largos bancos de piedra o de madera, mostradores de uso comercial donde se exponían los productos para su venta. El sistema, extendido por toda Europa Occidental (y que aún hoy podemos observar en ciudades del mundo islámico) presentaba la gran ventaja de facilitar la compra al cliente, pero llevaba aparejados así mismo no pocos problemas como podían ser el robo fácil y la obstaculización del tránsito viario. Así, sabemos cómo en Poitiers los comerciantes tenían prohibido vender en la vía pública los días de mercado y sólo podían hacerlo en ventanas para no molestar la circulación de carros y personas. Las ordenanzas de Córdoba incluyen entre sus capítulos varias disposiciones relacionadas con esta costumbre, en los que se denuncian algunos de los inconvenientes por ella provocados. Uno de ellos dice que "qualquiera que pusiere estançia de mercaduría de vedrio en la calle fuera de su tienda e no le pusiere guarda, e con el pasar e seruiçio de la gente la derribaren o quebraren las mercançías, que no sea obligado a pagarlas quien las quebrare", mientras que otro, relativo a los "ofiçiales e tenderos que sacan sus ofiçios e mercadurías fuera de sus casas o tiendas en las calles a sus puertas", prohibe que "durante el tienpo de ynbierno mientras llouiere e fizieren lodos saquen sus mercadurías de las puertas afuera de sus casas". ${ }^{(15)}$

Ciertas profesiones llegaron incluso a colocar, en plena vía pública, sus materias primas, útiles, banquetas, perchas para secar paños y pieles, y realizaron allí diversas operaciones. En Burgos, las actas del siglo XV denuncian que muchos oficios --entre los que se cita con frecuencia a los acicaladores de cerrajería-- labraban en las puertas de sus casas impidiendo el paso a la gente; en 1436 fueron condenadas once personas en Sevilla "porque tenían tableros en que fasían sus obras en las 
calçadas e non estauan desembargadas por do pasare la gente"; y en Ciudad Rodrigo se mandan retirar en 1496 "los tableros que en las delanteras de las casas se levantan faziendo oscuras e angostas las dichas calles". ${ }^{\text {(16) }}$

Las disposiciones que el cabildo de Córdoba emitió sobre el particular fueron muy abundantes. Una ordenanza del año 1500 disponía "que los curtidores ni otras personas no tiendan cueros en los adarues de la cibdad ni cuelguen lana, cueros ni otras cosas en la calle real por do pase la gente"; en 1493 el cabildo mandaba que "en las calles que están esteras de esparto o de aneas o marcos o tablas u otras cosas fuera de los ajimezes que los quiten dentro del terzer día"; y las ordenanzas de alarifes añaden: "los barueros que tienen tyendas en calles pasaderas fuera de plaças e rinconadas que tengan las muelas asentadas e puestas dentro de sus tyendas e no fuera porque enbargan las calles e atajan los andenes de la gente" y que los esparteros, cordoneros, asteros, aljabibes y otros oficios "que cuelgan perchas e ponen sombras, que ninguno pueda ponerlas ni sacarlas más afuera de quanto es la orden de salida del agimez o tejadillos que están sobre las puertas de sus casas, que son quatro pies de salida, porque ay muchos ofiçiales que después de colgadas las perchas o las sombras las sacan con cisques o con uaras mucho trecho afuera de manera que ocupan las calles e el pasar de la gente".(17) Todo ello nos da buena idea del carácter "callejero" de la industria y el comercio urbanos y de la escasa distinción que existe en la época entre las actividades desarrolladas en la calle y las que se realizan dentro de las tiendas.

Los citados son sólo algunos ejemplos de una realidad común a todos los centros urbanos medievales. A fuerza de extenderse los establecimientos acabaron por impedir la circulación y amenazar las reglas más elementales de higiene. Los bancos y útiles de los artesanos obstruyeron las calles a pesar de las numerosas y reiteradas medidas tomadas por los municipios para impedirlo. $Y$ así, en Nimes fueron designados en 1270 unos comisarios con la misión específica de poner fin a tales abusos; en Narbona aparecen personajes similares hacia 1291, mientras que un estatuto de los jardineros de Toulouse de 1465 les obligaba a retirar en un plazo de cuatro días todos los enseres de su oficio acumulados en las calles; y en Córdoba, el cabildo municipal ordenaba en 1496 al alguacil mayor y los diputados del mes "que les hagan meter los bancos en sus tyendas a los menestrales". ${ }^{(18)}$ Pero nada de ello parece haber servido para poner fin a las costumbres de unos trabajadores que gustaban 0 , cuando menos, veían conveniente realizar sus labores enmedio de las vías; así lo demuestran las constantes ventas y arrendamientos de poyos, bancos y otros elementos exteriores que, adosados a las fachadas de las viviendas, servían para llevar a cabo ciertos trabajos, como pusimos de relieve con anterioridad.

A esto habría que añadir la presencia de tenderetes y puestos ambulantes que cada día, y especialmente en los de mercado, eran 
colocados en las principales calles de la ciudad por un nutrido grupo de campesinos y pequeños comerciantes que, eventualmente, venían a vender los productos por ellos mismos elaborados; vendedores que llevaban su carga sobre sus animales o sus hombros, que vendían en pequeños caballetes de tabla o en el suelo y que cada día surtían a la ciudad de legumbres, leche, hierbas medicinales o pescado. Gentes, en fin, como los que aparecen en el Cris de Paris, obra del siglo XV, cuyos grabados representan vendedores o artesanos ambulantes, cada uno acompañado por una leyenda en letra gótica referida al grito usual mediante el cual atrae al cliente: lecheras con sus jarros en la cabeza, hortelanos con sus asnos cargados de espinacas, y otros muchos. Es lógico, pues, que todo este mundo colorido, abigarrado y carente, además, de una reglamentación bien definida, provocara multitud de problemas circulatorios en las calles más importantes y concurridas de las ciudades medievales y obligara a las justicias municipales a intervenir en reiteradas ocasiones para tratar de conservar, en la medida de sus posibilidades, el buen estado de los pavimentos y las calzadas y la libre circulación de hombres, animales y carros por el casco urbano.

\section{LA PAVIMENTACIÓN DE LAS CALZADAS}

Durante los siglos XIV y XV, por todas las ciudades del Occidente europeo, resuenan los ecos de los trabajos de pavimentación efectuados en las calles. Con anterioridad al siglo XIII apenas existen noticias sobre la colocación de pavimentos, lo que no significa que hasta esa fecha no se pavimentasen (la técnica fue conocida tanto en el mundo cristiano como en el musulmán durante toda la Edad Media), sino que fue a partir de la misma cuando los poderes locales tomaron mayor conciencia de su necesidad y cuando las nuevas condiciones socio-económicas impusieron su utilización definitiva.

¿Por qué se extiende y generaliza el uso de pavimentos en la Baja Edad Media? Dos son los principales tipos de razones que suelen barajar quienes se han ocupado del tema: las de carácter económico y las de carácter higiénico. Jean Pierre Leguay pone el énfasis en motivaciones de tipo comercial, tales como la generalización del caballo calzado con herradura de hierro como animal de tracción o el empleo, cada vez más frecuente, del carro de dos o cuatro ruedas como medio de transporte. ${ }^{(19)}$ Esta idea se expresa en diversas ordenanzas y disposiciones de la época que ponen el acento en la mejora que de cara al tráfico viario y a la fluidez de la circulación ofrecían los suelos pavimentados. Así ocurre en el caso de Segovia donde se dice, en el año 1500, que "el sitio desta cibdad está en lugar áspero e las calles se andan con mucho trabajo, especial en el tienpo de inbierno que desis que esa dicha cibdad es muy lodosa e los arrabales della, e que fasta aquí han tenido mucha nesesydad de se adobar e empedrar las calles"; en el de Zaragoza, donde los días de lluvia 
se tenía que caminar por la ciudad con el barro hasta las rodillas, mientras que las huellas dejadas en el piso húmedo por carros, caballos y peatones quedaban marcadas cuando éste se secaba produciendo irregularidades en el suelo que entorpecían el tráfico; o en el de Mallorca, cuyas calles, como las de cualquier ciudad de la época, eran aptas para convertirse en lugares llenos de barro en invierno y en nubes de polvo en verano. ${ }^{(20)}$

Sin embargo, en otros lugares la relación entre pavimentación y salud aparece mucho más nítidamente marcada. Así ocurre en Salamanca, cuando el infante Don Juan ordena a sus vecinos, en 1497, empedrar las calles principales porque "a causa de los muchos e grandes lodos que en ella ay de contino" proliferaban las enfermedades; y en Sevilla, en cuyas Actas Capitulares se recoge un expresivo testimonio según el cual las calles debían ser pavimentadas "por el grand prouecho que dello se recresçe a todo el pueblo desta çibdad, porque estando las dichas calles soladas están linpias e se excusan dellas los lodos en tiempo de ynvierno e las suziedades e otras cosas fediondas que en ellas estauan cuando no estauan soladas...porque desde que se han solado las calles desta çibdad a plasido a Nuestro Señor que en esta çibdad no ha avido pestylençia como lo solía haber contynuamente en los años pasados, e las gentes biuen más sanas porque çesan los malos olores e otras cosas enpesçibles a la salud de las gentes". ${ }^{(21)}$.

A estas consideraciones de tipo socio-económico se vinieron a sumar otras de carácter cívico. En efecto, a la par que los poderes municipales desarrollaban una preocupación urbanística desconocida anteriormente, ponían en el aspecto ofrecido por su ciudad un índice a la propia organización y, si se quiere, a la propia capacidad económica del cabildo. La pavimentación se convirtió así en un motivo de prestigio urbano. Dato esencial en las descripciones y crónicas de las ciudades italianas de los siglos XIII y XIV es remarcar con satisfacción el hecho de que las calles estuvieran pavimentadas con su correspondiente sistema de' canalización de las aguas pluviales y residuales; en centros urbanos como Siena, Florencia o San Gimignano, la pavimentación asumía incluso el decisivo papel de servir de marco a la imagen de los edificios públicos y principales, alineados en calles y plazas, cuyas fachadas no podían ser entendidas $\sin$ el consiguiente buen estado de los suelos situados delante. ${ }^{(22)}$

Así pues, razones económicas, higiénicas y de prestigio o decoro urbano llevaron a las ciudades europeas a intensificar su preocupación por el tema del pavimento durante los últimos siglos de la Edad Media. Los trabajos de pavimentación no se emprendieron, con carácter general, en todas las ciudades europeas coetáneamente. Precursoras, en este sentido como en tantos otros relacionados con la urbanística, fueron las ciudades italianas, que hacia mediados del siglo XIV cuentan ya en su mayor parte con amplias zonas pavimentadas; las ciudades francesas e inglesas se integrarán en este movimiento durante los años finales del siglo XIV y primeros del XV: París conoce pavimentos desde la época de Felipe 
Augusto, pero la mayor parte de las ciudades importantes (Amiens, Douai, Dijon, etc.) sólo los tendrán a partir del siglo XIV, e incluso otras, caso de Poitiers, inician dicha pavimentación bien entrado el siglo $X V^{(23)}$

En los centros urbanos de la Península lbérica no será hasta finales de ese siglo cuando se emprenda de forma sistemática la pavimentación completa de las principales zonas urbanas, de aquellas donde radican los centros comerciales o del poder político de la ciudad, puesto que las calles marginales permanecen sin pavimento durante muchos siglos más. ${ }^{(24)}$ Buen ejemplo de esta práctica lo constituyen los casos de Segovia (con pavimentaciones iniciadas en torno a 1489), Madrid (hacia 1486) y la propia Córdoba, con trabajos emprendidos en 1493 . $^{(25)}$

En virtud de lo expuesto resulta evidente que durante la Baja Edad Media la mayoría de las calles de las ciudades hispanas, Córdoba incluida, eran terrizas y en ellas tuvieron un protagonismo fundamental los trabajos de allanamiento, limpieza y consolidación del firme, realizados al margen de la propia solución del empedrado. De forma que antes de hablar de la colocación de pavimentos conviene considerar las labores de acondicionamiento efectuadas sobre las calles terrizas que eran, y continuaron siendo aún durante bastante tiempo, las más numerosas en cada ciudad. Como afirma Salusbury-Jones en su estudio sobre la vida urbana en la Inglaterra medieval, un rasgo fundamental de dichas calles era que resultaba extremadamente difícil mantenerlas en un estado decente de conservación y esto es verdad tanto para los pavimentos como para los suelos terrizos. ${ }^{(26)}$

El principal problema al que parecen haberse enfrentado este tipo de calles era el de la formación de hoyos e irregularidades en el terreno. El cabildo estaba encargado de poner remedio a los mismos mandando "adobar" la calle en cuestión (expresión ésta que se utiliza siempre que se alude al arreglo de una calle no pavimentada) y repartiendo el costo de la obra entre sus vecinos. Por ejemplo, cuando en 1493 hubo de repararse la cordobesa calle de Abéjar, los alarifes comenzaron fijando las condiciones de los trabajos que se habían de hacer; luego pusieron éstos en pública almoneda $y$, tras ser adjudicados, dos jurados de la collación junto a cuatro vecinos de la calle se encargaron de repartir entre los habitantes de ella el dinero que debían entregar para costear la obra, a fin de recogerlo y dejarlo en poder de dos particulares hasta que los trabajos quedasen concluidos. ${ }^{(27)}$ El sistema seguido para la realización de las obras era siempre el mismo, con ligeras variantes --en algún caso, la valoración de las calles era hecha por los fieles, los diputados del mes u otros oficiales del cabildo, como en el caso de la calle de los Escribanos Públicos y la Rehoyada en 1479--. ${ }^{(28)}$

Los hoyos, zanjas y socavones debieron de ser tan frecuentes en las calles que incluso las ordenanzas municipales contemplaron el problema, mediante la prohibición de hacer "zahurdas, hoyos, poyos ni forados en la calle del rey" y de dejar cimientos viejos por debajo de las calles de tal manera que éstas se ahoyaran. ${ }^{(29)}$ Está claro que tales 
disposiciones nunca terminaron con los inconvenientes que pretendian evitar y aún a fines del siglo XV siguen apareciendo en la documentación municipal numerosas menciones sobre el arreglo de hoyos y agujeros que entorpecían la circulación de carretas y bestias y perjudicaban considerablemente a la imagen de la ciudad. Por ejemplo, en 1496 el cabildo de Córdoba ordenó reparar los hoyos situados entre las Puertas del Puente y del Sol (un lugar de los más concurridos de la ciudad por ser la calle que atravesaban en su recorrido todas las mercancías que entraban o salían por el puente mayor camino de Sevilla o Málaga) porque "están para peligro de las bestias que por ally van e vienen que traen bastimentos a la çibdad" y, en 1499, dispuso igualmente la reparación de otros hoyos abiertos en la calle de los Marmolejos y en la del Caño de Vecenguerra, vías ambas de considerable tráfico e importancia. ${ }^{(30)}$

De cualquier forma, y aún teniendo en cuenta la escasez de calles pavimentadas en comparación con las terrizas, a las que se puede calificar como de "normales" en la época, no cabe duda de que a finales del siglo XV, sobre todo durante los años $90 \mathrm{del}$ mismo, existió una preocupación seria por parte de los cabildos municipales de la Península en pavimentar las calles más importantes de cada ciudad y todos ellos realizaron trabajos concretos en muchas zonas, algunos de los cuales nos han quedado documentados. Aunque esta pavimentación siga teniendo, incluso durante todo el siglo XVI, un carácter minoritario, el fenómeno es lo suficientemente destacado como para ocuparnos de él, sobre todo por lo que supone de avance respecto a la situación urbanística preexistente y de novedad respecto al estado y utilización de las calles céntricas de una capital.

El sistema seguido para sufragar las pavimentaciones era similar al que hemos visto en la mejora y reparo de las calles de tierra: una vez decidida por el cabildo la calle o zona que convenía empedrar, los trabajos eran puestos en almoneda y, tras ser rematados, eran costeados por los vecinos de cada calle mediante el sistema de repartir entre ellos el monto total de los mismos. Cuando se trataba de reparar un pavimento dañado por el uso, el acopio de dinero se efectuaba del mismo modo. Así, cuando se ordenó empedrar diversas calles del centro de Córdoba en 1493 el cabildo señaló "que el repartimiento de lo que costare sea fecho en día de fiesta e por pregón e se reparta en los señores de las casas e en los que las tienen por uida"; y Las propias ordenanzas de alarifes regulaban dichos repartimientos al recoger, en su capítulo $85^{\circ}$--"de los empedrados que se mandan fazer en las calles a costa de los veçinos dellas"--, "que todos los repartimientos que se fizieran por barrios a costa de los vezinos fueran mesurados e repartidos por pertenençias". ${ }^{(31)}$ Idéntica costumbre fue adoptada en la época por ciudades como Palencia, Madrid y Plasencia, mientras que en otros lugares, caso de Burgos o Mondoñedo, cada vecino debía costear la instalación y el mantenimiento del pavimento correspondiente al trozo de calle situado ante la puerta de su vivienda. ${ }^{(32)}$ 
Tal sistema, que en principio podía parecer justo, motivaba frecuentemente las quejas de los vecinos afectados, puesto que no siempre les correspondía la culpa del deterioro sufrido por el pavimento, especialmente en las calles de tráfico intenso, "porque rompiéndolo toda la ciudad e su tierra, cada uno conforme a su ofiçio e trato, unos con bestias e otros syn ellas", no era razonable que sólo los vecinos ribereños pagasen los destrozos. ${ }^{(33)}$ A consecuencia de ello se adoptó un sistema mixto, utilizado ya desde fines del siglo XV, consistente en hacer costear las citadas obras en parte a los vecinos de la propia calle (máximos beneficiarios, sin duda, de las mismas), en parte a los de todo el barrio donde la citada calle se ubicaba. Así ocurrió en Córdoba el año 1493, cuando el cabildo ordenó "que las calles que están mandadas empedrar, que las tres quintas partes las paguen los señoríos de las casas e las otras dos quintas partes que las paguen los vecinos de cada collaçión de la calle que se empedrare". ${ }^{(34)}$

En ocasiones, cuando el coste de los trabajos resultaba excesivamente gravoso para los vecinos o el empedrado debía ser hecho en una zona de exclusiva competencia municipal, era el propio cabildo quien costeaba, total o parcialmente, las labore, destinando anualmente para ello un presupuesto que se nutría, tanto del ordinario dedicado a obras públicas, como de ingresos extraordinarios obtenidos a través de multas y sanciones. Esta práctica tiene su reflejo en la ciudad de Toledo, cuyas ordenanzas de 1502 disponen que "cuando se hubieren de empedrar las calles, quier se haga de nuevo, quier se repare lo empedrado, han de pagar sus pertenencias todos los vecinos, iglesias y monasterios, y la ciudad lo que tocare a las plazas y lugares públicos donde no ay pertenencia de particulares"; y el expediente de recurrir a las multas para sufragar la colocación de pavimentos fue utlizado con asiduidad en diversos centros urbanos de la época, como Segovia --donde diversas penas procedentes de los molineros fueron empleadas a tal fin en 1504-- o la propia Córdoba. ${ }^{(35)}$ En ésta, el cabildo ordenaba en 1498 devolver a unos molineros las piedras de aceña que les habían sido tomadas por algunos criados del alcaide Diego Fernández "so pena de çinco mil mrs. para los empedrados de la puerta del fierro", mientras que en otras ocasiones fueron aplicadas a tal fin las multas obtenidas de los particulares que no habían derribado sus poyos y calzadas en las calles por empedrar, las impuestas a los escribanos que no colgaron en la entrada de sus tiendas la tabla de los derechos que debían percibir o la satisfecha por un jabonero que fabricó jabón de mala calidad. ${ }^{(36)}$

Mediante una $u$ otra de estas modalidades se costeaban unos trabajos de pavimentación para los que existieron, en muchas ciudades del Occidente europeo, obreros especializados. En Amiens conocemos la presencia de un faiseur de caudries y en Blois de un Commis a faire les reparations de ponts e pavemenz, magistrados dependientes del cabildo y que controlaban a un amplio grupo de pavisseurs, chaussieurs y faiseurs de caudries, equipos de obreros o peones que se encargaban de la 
instalación y mantenimiento del pavimento viario. ${ }^{\left({ }^{37}\right)}$ La organización de tales trabajos en las ciudades castellanas parece haber sido diferente $y$, en el caso concreto de Córdoba, el empedrado de las calles solía ser puesto a pública subasta y rematado en el particular que ofrecía mejor precio y condiciones, de forma que las obras en cada zona eran realizadas por equipos diferentes bajo la supervisión de un magistrado urbano. Por ejemplo, en 1498 encontramos un albañil encargado de empedrar el puente de la Fuenseca, mientras que al año siguiente un equipo de peones empedraba la puerta del Hierro bajo el control y vigilancia del jurado Juan de Córdoba quien tenía "cargo de mirar cómo va la obra según se mandara hazer". ${ }^{(38)}$ Cuando no era posible seguir este sistema se recurría al obrero de las labores del cabildo, oficial a sueldo del municipio, como cuando en 1493 se ordenó al jurado Juan de Rojas "que faga al obrero de la çibdad empedrar un pedaço de la puente mayor de Córdoua". (39)

Finalmente, algunas ciudades dispusieron también de cargos especiales para velar por la conservación de las calles pavimentadas. En la ciudad francesa de Poitiers existió un paveur de la ville; en la de Troyes, un voyeur, y en París, un visiteur du pavé, todos ellos con funciones de vigilancia sobre los empedrados; en Inglaterra, estas figuras aparecen ya en el reinado de Eduardo I, cuando fueron elegidos en Londres cuatro surveyers of pavement por barrio, oficiales que fueron el precedente de los que en 1343 aparecen como serjeants of the wards y, del mismo modo, en la Sevilla del siglo XV se creó un veedor que venía obligado a recorrer periódicamente las calles de la ciudad y denunciar daños y roturas. ${ }^{(40)}$ No tenemos constancia de que en Córdoba haya existido un cargo especial dedicado exclusivamente a esa labor, de forma que la vigilancia era ejercida por los alarifes, diputados del mes, alguaciles, mayordomos y otros oficiales del cabildo, las más de las veces a petición directa y puntual del mismo; por ejemplo, en una ocasión se ordenó "que el alcalde mayor y Lorenço de las Ynfantas fagan ynformaçión de lo empedrado", y en otra que fueran los alarifes quienes viesen "los empedrados nuevos".

Todas estas obras se realizaban, sin embargo, sobre una superficie viaria muy reducida, coincidente con el área de los centros comerciales y políticos de la ciudad o con aquella donde los miembros de la oligarquía local tenían fijados sus intereses. ${ }^{(42)}$ ¿Qué zonas y calles de Córdoba estuvieron pavimentadas en la Baja Edad Media? Con anterioridad a fines del siglo XV sólo conocemos dos topónimos que hagan referencia indirecta a ese hecho: el de una calle "Empedrada" en la collación de Santa Marina y otra en la de San Lorenzo, pero ninguna mención explícita sobre labores de pavimentación. ${ }^{(43)}$ Estas sólo comienzan a ser abundantes en los años 90 del siglo XV, en los cuales sabemos que estaban empedradas las siguientes zonas urbanas: el puente mayor, la calle de la Platería desde la Puerta del Puente a la Puerta de la Pescadería; la calle del Potro, desde la citada Pescadería a la Puerta de Baeza; la calle de la Feria, la de Escribanía Pública, la plaza del 
Salvador y la actual calle Alfaros hasta la Puerta del Rincón; la Puerta del Hierro; la calle de los Marmolejos, la Espartería y Plaza de la Corredera hasta la calle de San Pedro; la calle del pilar de San Pablo y el portillo de la Fuenseca. ${ }^{(44)}$

Es decir, que se hallaba empedrado todo el centro comercial de la ciudad (eje sur-norte: calle de la Feria, Escribanía, Salvador, Puerta del Hierro; y eje este-oeste: Puerta de Baeza, calle del Potro, Puerta de la Pescadería, calle de la Platería, Puerta del Puente y puente mayor; así como algunas calles adyacentes, caso de la Espartería, Marmolejos y San Pablo); y posiblemente toda esta amplia zona fue empedrada por primera vez en 1493, cuando se mandó pavimentar derribando "todos los poyos e calçadas que oviere en un plazo de seys dias". ${ }^{(45)}$ Debieron de existir más calles pavimentadas repartidas por diversos puntos de la ciudad, allí donde era especialmente necesario por el tráfico comercial o donde convenía a los dueños de las viviendas, pero no nos han quedado testimonios sobre ellas.

Por lo que se refiere a la técnica empleada para la pavimentación, hay que indicar que difería mucho de unas ciudades a otras. En los lugares donde la carestía de piedra era muy acentuada la técnica más usada consistió en cubrir los suelos con ripio y cascajo; ese fue el caso de Sevilla, donde en 1424 se invirtieron trescientas setenta cargas de ripio para pavimentar la calle de la Alhóndiga, "para adobo della por la mucha agua e lodos que hay en la dicha calle". Otro sistema fue el de emplear ladrillos colocados de canto, unidos con arena seca o con mezcla de cal y arena según los casos. Este método, documentado también en la ciudad de Sevilla, podía resultar válido para las calles de poco tránsito y que no fueran de paso obligado para las carretas, pero no así en las concurridas, donde pensamos que el ladrillo era incapaz de soportar un tráfico intenso. ${ }^{(46)}$ En aquellas ciudades donde la piedra no escaseaba tanto, fue éste el material más utilizado. Tal es el caso de la mayor parte de ciudades francesas, inglesas o peninsulares, donde el granito, el cuarzo y otras piedras semejantes fueron empleadas en la pavimentación. Quizá ello explique que mientras en los documentos sevillanos la operación de pavimentar los suelos aparece denominada como "solar", en los de Córdoba y otras ciudades se habla siempre de "empedrar", dando a entender con ello el uso de distintos materiales.

El sistema seguido para instalar los empedrados fue muy parecido en todas partes. En Burgos se colocaban los cantos y guijarros sobre la tierra endurecida o se ponían losas de piedra unidas con argamasa o hasta con betún; en Segovia, se colocaban piedras menudas sobre una base igualada con arena, dejando canales para las aguas residuales; en Córdoba el método usado habitualmente fue el de enmarcar la zona a empedrar mediante sillares dispuestos de canto y colocar enmedio piedras pequeñas y redondeadas asentadas sobre una base de cal y arena. ${ }^{(47)}$ Aunque no lo sabemos con certeza, parece ser que dichas piedras procedían en su mayor parte de las canteras situadas en los términos de 
Posadas y Hornachuelos, lugares de donde se traían también las piedras de molino utilizadas en Córdoba y otras para la construcción; así lo testimonia el mandamiento capitular que ordena sean "prendados los vecinos de las Posadas cada uno por treçientos mrs. e que se traygan aquí las piedras para el empedrar de la puerta del fierro e aquí se le dará su salario". ${ }^{48)}$.

Pero el principal problema planteado por los empedrados fue, sin lugar a dudas, el de su mantenimiento. Incluso cuando se emplearon piedras de lárga duración --y ésta ha sido calculada por Jean Favreau en torno a los treinta años, según documentos de la época--, el estado de los pavimentos no pasaba de ser mediocre y de exigir intervenciones periódicas para reparar los desperfectos ocasionados. ${ }^{(49)}$ Buena parte de los daños eran efectuados por los propios al realizar agujeros y zanjas; en Burgos se castigaba con una fuerte multa a quien abriese agujeros en los empedrados para las fiestas de mayo, mientras que en Córdoba las ordenanzas prohibían a "los que facen algaradas o lidian toros ronper los enpedrados de las calles para facer talanqueras" y a los caldereros "fincar ferrones en lo enpedrado ni romperlo" so pena de 30 azotes. ${ }^{(50)}$ La otra causa fundamental de deterioro era el paso de las carretas, sobre todo de aquéllas más grandes que transportaban hierro y otras materias igualmente pesadas, de ahí que cuando se empedraron las calles céntricas de la ciudad en 1493 el cabildo ordenara "que lo que puedan entrar en acémilas no entren en carretas e lo que no pudieren entrar en acémilas entren en carretas, pero que no entren por lo empedrado nuevo" y como es lógico que una disposición de este tipo ocasionara no pocas dificultades a los arrieros y transportistas que llegaban a Córdoba (alquiler de mulas, traslado de mercancías, costes adicionales), ya en 1498 aparece matizada por el cabildo al acordar "que entren por la Puerta del Rincón los mercaderes de hierro, herraje e astería, según se contiene en el mandamiento de Córdoua e que vayan a la cal de la Heria con tanto que se obliguen de empedrar lo que se desempedrare por donde pasan con las carretas". (51)

En definitiva, eran muchas las circunstancias que podían ocasionar desperfectos en las calles pavimentadas, y aunque el cabildo obligaba en 1493 a "que todos los vecinos de las calles de lo empedrado nuevo tengan enfiesto e fecho el enpedramiento cada uno su pertenençia", ${ }^{(52)}$ lo cierto es que rara vez los pavimentos presentaban un aspecto cuidado y regular. Antes bien, por lo general se hallaban llenos de agujeros, piedras desprendidas, irregularidades y badenes, que en ocasiones debían de dificultar más aún la circulación por ellas que por las mismas calles terrizas. Buen ejemplo de ello es la afirmación de A.J. Albardonado de que la primera exteriorización del caos urbanístico que propios y forasteros observaban a su llegada a la Sevilla del Seiscientos era el deficiente estado de sus pavimentos. ${ }^{(53)}$

Un último aspecto que conviene mencionar en este apartado sobre pavimentación de calles es el de la colocación de aceras o "calzadas", 
como frecuentemente se las denomina en la época, en las márgenes de las vías. Aunque no suele destacarse este hecho, la mayoría de las ciudades medievales disponían de aceras realizadas por los propios vecinos delante de su fachada, caso de la extremeña ciudad de Plasencia. ${ }^{(54)}$ Las aceras no solamente se instalaban en calles pavimentadas, sino también en las de tierra, a fin de evitar que el agua y los lodos penetraran en la casa o rozaran con paredes y puerta. Como éstas eran realizadas de forma particular por cada individuo, las calles ofrecían un aspecto muy irregular, pues ante cada casa tenían las aceras una anchura y altura diferentes, estaban hechas con distinto material (granzas de tierra, argamasa, ladrillo) y su longitud era muy variable. El municipio cordobés intentó remediar esta situación ordenando "que ningún ome faga calçada en altura ni andén a la puerta de fuera de su casa en la calle sin licençia de la cibdad e si la cibdad diere licençia fagan las calçadas parejas de largo a largo juntanto con sus vezinos de manera que todo el barrio sea una calçada de un cabo e otra del otro, de lado a lado acordándolo con los alarifes, que ellos señalen el ancho, largo e alto que será de salida en calles medianas el ancho del cuarto de la calle e un palmo en altura en el rostro delantero sobre el suelo de la calle". ${ }^{(55)}$ Pero no creemos que esta disposición pusiera fin a la heterogeneidad que, en cuestión de aceras, como de los restantes elementos urbanísticos, presentaban las calles medievales.

\section{LIMPIEZA, HIGIENE Y SALUBRIDAD URBANAS}

La imagen que ha llegado hasta nosotros sobre las condiciones de vida en las ciudades medievales, y que coincide en líneas generales con la que nos presentan los testimonios de la época, es la de que se trataba de núcleos de población con gravísimos problemas higiénicos y con un alto grado de suciedad. Los autores que han abordado este tema --como es el caso de Antonio Collantes para Sevilla o Higounet-Nadal para el de Périgueux-- han llegado a la conclusión de que aquellas ciudades bien podían ser calificadas de "anti-higiénicas", pues el índice de contaminación y suciedad que sus habitantes debían soportar conllevaba tantas dificultades y peligros como los que la moderna polución plantea en nuestras grandes urbes. ${ }^{(56)}$ Es indudablemente cierta la idea apuntada por Jean Pierre Leguay de que la contaminación de aquélla época parece más "natural" que la nuestra, es decir, más orgánica o mineral que química o industrial, pero también lo es que no por ello resultaba menos perjudicial para la salud; los múltiples testimonios dejados por los contemporáneos, la gran diversidad de descripciones y anécdotas llegadas hasta nosotros, las numerosas ordenanzas y disposiciones dictadas por los gobiernos locales, son lo suficientemente expresivos como para afirmar la gravedad de una polución doméstica y colectiva a la que los hombres de la época hubieron necesariamente de prestar atención. 
Ellos mismos se dieron ya cuenta de los múltiples perjuicios que a la vida cotidiana de una comunidad causaba ese hecho y, con frecuencia, lograron relacionarlo con la aparición o el agravamiento de epidemias y enfermedades. Leguay afirma que, desde el siglo XIII, las ordenanzas de muchas villas, incluidas las más pequeñas, se quejan constantemente de la existencia de muladares (depósitos de basuras) a los que se denuncia como responsables de las pestilencias, del "aire infecto y corrompido" a la par que se les atribuyen muchas de las dificultades de circulación, acumulación de escombros y accidentes que tenían lugar en la vía pública. ${ }^{(57)}$

La toma de conciencia sobre los peligros procedentes de la suciedad y la contaminación acumulada en los espacios públicos --así como de la influencia que la misma tenía en la reputación de una villa (instalación de extranjeros en ella, auge de su comercio) y, sobre todo, en el propio bienestar de sus habitantes-- despertó, entre los regidores municipales y los principales vecinos de cada ciudad, una seria preocupación por la higiene pública, consecuencia de la cual fueron las numerosas disposiciones que, a partir de los siglos XIV y XV, se dictaron para conservarla. Lo que ocurre es que en el mundo urbano del siglo XV existía un claro desfase entre la preocupación que sus gobernantes mostraban por mejorar las condiciones de higiene y salubridad en el interior de la villa y la colaboración que el común de los vecinos prestaba a ello. Es más, aunque se hubiera conseguido concienciar a todos los habitantes de una ciudad del perjuicio que la acumulación de basuras y suciedad en las calles ocasionaba, difícilmente se les podría haber obligado a obedecer con integridad las ordenanzas dictadas por el cabildo en esa materia. Y ello porque la causa principal de la "antihigiene" reinante en aquellas ciudades no era ni la incompetencia de los gobiernos municipales, ni la dejadez o el egoísmo de los vecinos, sino tan sólo la inexistencia de una infraestructura urbana mínima que permitiera hacer frente con garantías a las necesidades de limpieza, sin tener que recurrir a ordenanzas, en la mayor parte de los casos, difíciles de cumplir en la práctica.

La falta, no ya de un sistema de alcantarillado adecuado, sino ni tan siquiera de una red de cloacas, impedía la correcta evacuación de las aguas residuales o de la procedente de lluvias e inundaciones. Tampoco existía una organización mínima en lo que se refiere a la recogida de los residuos orgánicos dejados por el hombre, del estiércol de los animales que compartían con él el espacio urbano o de los diversos materiales residuales de carácter doméstico que, en una buena parte de los casos, iban a parar a las vías públicas sin que el poder municipal dispusiera de medios de control suficientes para garantizar el cumplimiento de sus propias ordenanzas. 
Así pues, el principal problema a que la ciudad tenía que hacer frente para conservar las condiciones higiénicas en su interior era el de cuidar la limpieza de las calles. En principio, el cabildo municipal era el encargado del mantenimiento en buen estado de las vias públicas, tanto desde el punto de vista de su infraestructura como de sus condiciones higiénicas, y es por este motivo por lo que se nos han conservado desde el siglo XIV abundantes disposiciones sobre el particular en las distintas ciudades europeas. Con anterioridad a esa fecha, apenas si existen referencias sobre las actividades de limpieza urbana, sobre todo porque, como señala Ernst Sabine para el Londres bajomedieval, hasta fines del siglo XIII ésta se realizaba más siguiendo antiguas costumbres que por una ley escrita. ${ }^{(58)}$ Pero desde el siglo XIV, los oficiales municipales planean y ordenan esos trabajos $y$, en virtud de ello, dictan una serie de disposiciones que tenderán a mejorar la conservación de las calles.

Para la ciudad de Córdoba, los textos sólo empiezan a ser abundantes en la segunda mitad del siglo XV y es sólo a partir de esos momentos cuando comenzamos a estar informados de las medidas tomadas. El municipio cordobés nombraba anualmente uno o dos mayordomos que, entre otros cometidos, tenían como misión fundamental la de mantener limpias las calles de la ciudad, tarea nada fácil según ponen de manifiesto los diversos capítulos de ordenanzas y acuerdos capitulares conservados. No en todas partes fueron estos los oficiales municipales encargados del cuidado y vigilancia de las calles; en otros lugares, caso de la cacereña villa de Tobarra y de la cordobesa Cañete de las Torres, fueron los almotacenes quienes debieron denunciar y controlar los daños realizados contra la higiene urbana, hasta el punto de ser multados "si tercero día estuviere vestia o basura en la calle e non lo denunciare". ${ }^{(59)}$

En el caso de Córdoba, el nombramiento de los mayordomos solía efectuarse el día de San Juan de junio (fecha en la que el cabildo renovaba buena parte de los cargos municipales y sancionaba a los veedores designados por las distintas corporaciones artesanales) y quien ocupaba dicho cargo un año no podía ser reelegido en él hasta pasados otros dos, según testimonia un acuerdo capitular de 3 de junio de 1499 que preveía el nombramiento de un mayordomo en las citadas condiciones. ${ }^{(60)}$ En la labor de mantener la limpieza de las calles, su actuación quedaba controlada por dos oficiales del cabildo: en primer lugar, por el alcalde mayor, a quien se autorizaba a vigilar el comportamiento de los mayordomos "e si ay negligençia en el linpiar de las calles los pueda penar e prender" y, en segundo lugar, por los diputados del mes, a quienes se indica "tomen cargo de ver los capítulos de los mayordomos sobre la linpieza e los apremien que los cunplan". ${ }^{(61)} \mathrm{Si}$ los mayordomos no lograban mantener suficientemente limpias las calles, el cabildo podía encargar dicho cometido a determinados particulares cuya 
actuación sería sufragada por los propios mayordomos y en no pocas ocasiones el cabildo empleó ese argumento para obligarles a efectuar la limpieza. ${ }^{(62)}$ Pero a pesar de las amenazas parece que las calles de la ciudad nunca estuvieron suficientemente limpias o, al menos, no al gusto del cabildo, puesto que son constantes los acuerdos mediante los que se ordena a los mayordomos retirar las basuras y suciedades acumuladas en ellas, como el tomado en febrero de 1493 para "que se diga a los mayordomos como está la cibdad mucho suzia, que la manden luego linpiar de las inmundiçias que ay en las calles, si no que la justiçia les dará la pena que se fallare por derecho". ${ }^{(63)}$

De cualquier modo, es interesante destacar el hecho de que existieran en la época unos oficiales del cabildo cuya misión estaba expresamente relacionada con la higiene pública. En ciudades como Sevilla, Burgos o Zaragoza no parece que hayan existido oficiales semejantes, sino que más bien la limpieza de las plazas y las calles era encargada a particulares que se comprometían a efectuarla durante un cierto período de tiempo y en una zona señalada, a cambio de un salario acordado con el municipio. ${ }^{(64)}$ Por supuesto que la presencia de esos oficiales no implicaba la existencia de un servicio organizado de recogida de basura o de mantenimiento de la red viaria. En la época, ese hecho constituía un avance excepcional que se dió en muy pocos lugares. Leguay destaca el caso de Amiens, donde el trabajo de recogida debía ser realizado cada día, antes de las ocho de la mañana, según ordenanzas del siglo XV, mientras que en París no se habría dispuesto de un servicio eficaz de recogida de basuras y limpieza de calles hasta el año 1511. ${ }^{(65)}$ Evidentemente, un servicio de similar eficacia en ciudades como Córdoba no fue organizado sino hasta mucho después, aunque existieron ciertos precedentes como el citado por Maria Asenjo para la ciudad de Segovia donde un acuerdo del concejo de 1493 estableció que todos los sábados recorriera las calles un carro con varias personas encargadas de limpiarlas y retirar las basuras en ellas acumuladas y el de Guadalajara, donde funcionó un servicio diario de recogida de basura por un carretero a partir del año $1500 .^{(66)}$ De todas formas, lo cierto es que la puesta en práctica de tales servicios tampoco garantizaba su adecuado funcionamiento; aún en el siglo XVII, tras encargar el cabildo sevillano la recogida de basuras a un equipo permanente de doce carros en 1620 , hubo de suprimirlos en breve, al no mejorar en modo alguno las condiciones higiénicas de la urbe y suponer sólo un gasto extra para el presupuesto municipal. ${ }^{(67)}$

Por otra parte, la intervención de los particulares, de los vecinos de cada barrio, en el mantenimiento de las vías públicas no era en absoluto desdeñable. En primer lugar, porque igual que ocurre en el caso de otras ciudades, hubo ocasiones en que uno o varios individuos se comprometieron a efectuar la limpieza de la ciudad cuando la sola actuación de los mayordomos no bastaba, tal y como ocurrió en mayo de 1493 cuando los capitulares "platicaron sobre la linpieza de la cibdad, de como los mayordomos no la fazen como deuen, que se busque si hubiere 
persona que tengan la cibdad linpia abligándose a tenerla linpia e los muladares que se fagan donde es razón";;(68) y, en segundo lugar, porque en ciertos casos los vecinos de cada calle tenían la obligación de cuidar de la misma. Desde luego, no existieron en Córdoba ordenanzas del tipo de las que descubrimos en algunas ciudades y villas de la época para que cada vecino mantuviera limpio el sector de calle situado delante de su casa: Londres 1372, Coventry 1421, en Bristol se establece incluso un horario especial para la limpieza, mientras que en Ipswich, hacia 1541, se ordenaba a cada persona limpiar la puerta de su domicilio cada sábado; en Poitiers, la regla fundamental era que cada vecino limpiase la parte delantera de su casa --chacun en droit soi-- y llevase las basuras fuera de la villa, llegando a ordenarse en 1479 que dicha limpieza fuera efectuada una vez a la semana. ${ }^{(69)}$

En Córdoba se obligaba a que los caballeros de premia contribuyeran a mantener limpias sus zonas de residencia, si bien es difícil precisar en qué medida y de qué forma intervenían en tal limpieza, que se evidencia por un acuerdo en el que se ordena "que los jurados de Córdoua digan a los caualleros de premia de sus collaçiones que tengan sus calles linpias". ${ }^{(70)}$ Mientras que la actuación de los particulares se manifiesta en la limpieza ocasional de una calle o zona concreta. Por ejemplo, en 1493 el cabildo ordena descubrir a quienes habían ensuciado la calle de Gonzalo de León para que los mismos culpables fuesen los encargados de limpiarla, si bien, a juzgar por la información que proporcionan las actas, debieron tener mucha dificultad en encontrar a tales sujetos y en hacerles limpiar la citada calle, puesto que la misma disposición se repite los días 18, 20 y 27 de marzo y 15 y 27 de abril y, en definitiva, ignoramos si al final consiguieron que fuera efectuada tal limpieza; lo mismo ocurrió en 1499 con una calle cercana a la iglesia de San Bartolomé "que está mucho suzia, que la tienen ensuçiada los vezinos comarcanos ... que los mayordomos la vean e ayan ynformaçión quién la ensuçió e la manden linpiar a costa de quien la ensuçió". ${ }^{(71)}$

Pero lo que resulta claro es que la actuación conjunta del cabildo, a través de sus mayordomos, y de los vecinos de cada sector urbano resultaba insuficiente para mantener las calles libres de inmundicias, de modo que cada vez que se celebraba alguna festividad importante o visitaba la ciudad algún personaje real el concejo tenía que proceder a adecentar el habitualmente poco presentable aspecto ofrecido por el espacio público urbano. Así, en 1493 se ordenaba a Juan de Luna "fazer linpiar las calles donde viere que cumple" para el día del Corpus Christi, y, en 1497, "que el jurado Pedrosa tenga cargo de pregonar las cofradías e fazer barrer las calles para la fiesta". ${ }^{(72)}$

¿Cuáles eran las principales causas que contribuian a llenar las calles y plazas de suciedad y contaminación y hacer baldíos, en la mayor parte de los casos, los trabajos y la preocupación del cabildo por el tema? Dos podemos destacar como las máximas responsables: la acumulación 
de basuras y residuos orgánicos en lugares no señalados para ello y la acción contaminadora de las aguas.

\section{Basuras y residuos orgánicos}

Quizá la que contribuía en mayor medida a la falta de higiene en las calles fuera la primera de las tres causas señaladas, destacando en este terreno la formación de muladares, vertederos de basuras y estiércol arrojados en cualquier lugar por los vecinos de la ciudad. No cabe duda de que debió de constituir un verdadero problema para las poblaciones bajomedievales la evacuación de tales residuos, puesto que al no existir un servicio organizado que atendiera tales necesidades, cada familia o individuo particular era responsable de la recogida de los restos originados en su casa y establos y de hacerlos desaparecer sin ocasionar perjuicios a la villa.

La mayoría de los concejos de la época tenían lugares especiales designados como vertederos, tal como ocurría en ciudades como Burgos y Segovia y en villas como Piedrahita, El Barco y Tobarra. ${ }^{(73)}$ De igual modo debieron de existir en Córdoba lugares designados al efecto, aunque desconozcamos cuáles eran; así se evidencia, al menos, a través de los acuerdos capitulares que, de vez en cuando, recuerdan a los mayordomos su obligación de vigilar que los muladares se hicieran en los sitios señalados para ello. ${ }^{(74)}$

Pero tanto en Córdoba como en Sevilla, como en cualquier otra ciudad del Occidente europeo, el problema era que no se respetaban las disposiciones municipales que acotaban determinadas áreas para hacer los muladares; y así, las múltiples callejas sin apenas tránsito, las barreras o solares sin edificar o cualquier casa vacía, eran lugares elegidos por los vecinos para arrojar los restos y convertirlos de ese modo en estercoleros. Como afirma Jean Pierre Leguay, todo espacio deshabitado servía para arrojar las basuras, estiércol, aguas sucias, tripas y pellejos dejadas por los carniceros, huesos, cadáveres de perros o de caballos o de los mismos hombres víctimas de alguna agresión. ${ }^{(75)}$ Parece ser que los lugares preferidos para formar muladares eran aquéllos situados junto con alguna pared, en algún solar desocupado, o junto a la muralla de la ciudad, en la parte exterior de la misma; ${ }^{(76)}$ en este sentido, las ordenanzas cordobesas de 1435 sancionaban a "qualquiera que echare estiércol por çima de los adarues" y las de alarifes de 1493 prohibían echar "borujo ni estiércol en la caua del adarue", ni hacer "allegamiento de basura o de estiércol, ni de tierra, ni de piedras a pared agena". ${ }^{(77)}$ Tremendamente expresiva de los perjuicios ocasionados por tal costumbre resulta la denuncia de los vecinos de la calle Pellejería en Segovia quienes, en 1475, protestaron de un muladar formado en la misma cuyas basuras llegaban hasta las casas habitadas, humedecían y derribaban las 
paredes de las mismas y ocupaban varios caminos de paso que estaban cerca. ${ }^{(78)}$

Cuando los muladares se formaban en zonas inadecuadas, el cabildo solía intervenir ordenando desaparecieran, pero ello no impedía la proliferación de los mismos, unas veces por falta de interés y otras por falta de recursos económicos con que llevar a cabo su limpieza pues, como indica Antonio Collantes, la operación resultaba muy costosa y una vez limpios el vecindario volvía a amontonar en ellos sus basuras. En 1498, el cabildo de Córdoba ordenó que nadie acudiese a arrojar "estiércol ni basura en el muladar junto con el arroyo en linde de la huerta de la golondrina", bajo pena de que en el camino hasta la cárcel, situada en la plaza de la Corredera, los alguaciles que le hubiesen apresado le fuesen azotando; y en 1499 dispuso limpiar "el çerro del muladar" que había sido denunciado por el jurado Alfonso García, de manera "que quedase por cosa pública para que la çibdad faga dello lo que mandare e no sea para solar de ninguna persona". ${ }^{(79)}$ Disposiciones idénticas a las que se perciben en el resto de la Península, como en el caso de Guadalajara cuyas ordenanzas indican "porque dicen que en la villa hay muladares e esto es dañoso a los vecinos della, que los almotacenes lo requieran e el que tuviere ahora muladar le digan que lo eche fuera hasta treinta días e si no lo echare peche siete mrs. de la nueva moneda e sea tenido de sacarlo; e los que de aquí adelante hicieren que los prendan por esta misma pena e los hagan echar a su costa". ${ }^{(80)}$

Aparte de la existencia de estos muladares, repartidos por diversas zonas de la ciudad, los más importantes se encontraban situados junto a los adarves de la misma; en Córdoba, hallamos uno en la Puerta del Rincón y es posible que, en este caso, se tratase de un lugar autorizado para ello, puesto que en las actas capitulares de 1479 lo citan sin aludir a su limpieza ni a los posibles perjuicios por él ocasionados. ${ }^{(81)}$ Pero en la mayor parte de los casos los acuerdos capitulares ordenan la desaparición de los mismos; así ocurre en el año 1497 con sendos muladares instalados en la Puerta del Sol ---"que los mayordomos de la cibdad sepan quien fizo un muladar e a su costa lo manden alinpiar, el qual está en la puerta del sol"-- y en la de Andújar -.-."que alrededor de la puerta de Andújar que un vezino o dos tengan cargo de quien echare una carga de basura allí que le fagan echar diez cargas dallí e que se dé mandamiento"--;(82) y en 1498 dicha disposición se extendió a todos los situados junto a los muros de la ciudad, al indicar el cabildo "que los mayordomos de Córdoua fagan linpiar los muladares que están junto con los adarues daquí a diez días e lo echen los que son en cargo so pena que a su costa se echare". ${ }^{(83)}$

Los muladares se formaban en buena parte debido a la acumulación de residuos orgánicos producidos por el hombre (restos de comida, cacharros, detritos, etc.). Aunque en algunas casas existían pozos negros para depositar ese tipo de desperdicios, no debemos despreciar la importancia que habrían tenido en la formación de los muladares y en el 
mal estado higiénico de las propias calles, porque hay que tener presente la dificultad que supondría para los habitantes de la ciudad deshacerse de tales residuos, especialmente cuando eran producidos a gran escala como en el caso de las instituciones religiosas u otras comunidades. Hasta tal punto llegó a suponer un problema este hecho que, en algunos casos, las monjas del monasterio de Santa Clara obligaron, a quienes arrendaban tiendas de su propiedad, "a linpiar cada año a sus costas toda la basura que en el dicho monasterio se fiziere, de tres en tres meses, tanto que no sea basura de aluañilería ni de sumideros ni de nesçesarias, e si asy no lo fizieren el conuento lo fará linpiar a costa de los arrendadores ... e que le den a los arrendadores la abadesa e monjas cada año, para ayuda de la dicha linpieça, dosientos mrs. pagados por San Juan Bautista de cada año". ${ }^{(84)}$

Pero lo que contribuía en mayor medida a la existencia de los muladares era el estiércol resultante de todos aquellos animales que compartían con el hombre el espacio urbano, estiércol que se acumulaba no sólamente en los muladares, sino en plena calle, cerca de las viviendas, en los lugares donde los animales lo habian dejado. Parece ser que en los pueblos ingleses de la Baja Edad Media era habitual que cada casa tuviera a su puerta un montón de estiércol que obstaculizaba las calles. Según ha demostrado Bárbara Hanawalt, muchos casos de los coroners' rolls mencionan montones de estiércol en la calle o envuelven a personas que llevan su estiércol a campo abierto; incluso un padre y su hijo, tras asesinar a la madre, la enterraron bajo el montón de estiércol que había a la puerta de la casa. ${ }^{(85)}$ Igual ocurría en Córdoba, por más que las ordenanzas impusieran sanciones a quienes así se comportaban, como muestran las de 1435 al ordenar que "todos los que echaren estiércol en la calle o bestias muerta o quemaren estiércol en la calle, paguen doze mrs. al almotacén, saluo el día de San Juan Bautista, que es costunbre de quemar e fazer fogueras". ${ }^{(86)}$ Jean Pierre Leguay ha destacado la costumbre tan extendida entre los habitantes de las ciudades bajomedievales --muy enraizados aún en el mundo rural-- de mantener en sus propias casas diversas especies de animales domésticos a los que con frecuencia dejaban sueltos por las calles o ante las puertas de su vivienda, provocando así que hombres y animales compartiesen un espacio limitado y ocasionasen graves peligros: en primer término, por el riesgo de infecciones que suponía la orina y excrementos de esos animales $y$, en segundo, por los problemas de tráfico viario a que daban lugar, obstaculizando el paso de las carretas o de los propios viandantes o haciendo peligrar la exposición de mercancías en tiendas y mercados. ${ }^{(87)}$

Un animal omnipresente en la época es el cerdo. Leguay cita el caso de la ciudad de Reims, donde los estatutos de la cofradía de panaderos de 1454 especifican que los miembros de la profesión no dejaran en adelante circular sus cochinos a las puertas de sus establecimientos como hasta entonces se había hecho; Favreau para el caso de Poitiers, Higounet-Nadal para el de Périgueux, Valdeón para el de 
Burgos, María Asenjo para el de Segovia y Elisa Carolina de Santos para los de Béjar y Plasencia, señalan igualmente las continuas prohibiciones municipales de que los cerdos circulasen sueltos por las calles y los numerosos problemas que ello ocasionaba. Bárbara Hanawalt llega incluso a decir que no sólo andaban sueltos por la calle, sino en el interior de los propios hogares, de manera que frecuentemente aparecen denuncias porque mordían a los niños y la ley les obligaba a llevar un bozal en el hocico. ${ }^{(88)}$

La presencia de los mismos por las calles de Córdoba resultaba también muy habitual y hasta tal punto abundante que las ordenanzas de 1435 prohibieron mantener más de tres cochinos por familia, denunciando a la par los perjuicios y suciedades ocasionados por ellos en las calles, huertos y viñas: "Otrosy, porque el criar de los puercos muchos en la cibdad viene mucha suziedad en ellos andando por las calles, e otrosy aún muchos puercos que se crían ayuntadamente que por fuerça han de salir fuera, toma el pueblo daño asy en los exidos como en las huertas e viñas, defendemos e mandamos que daquí adelante vezino ni morador de la cibdad no sea osado de criar puercos dentro de la villa, saluo que pueda tener cada uno en su casa tres puercos sin caloña e que los guarde en tal manera que no fagan daño a ningunos, e qualquiera que más puercos toviere de tres en su casa ni dentro en la cibdad, que peche por cada puerco de caloña por cada vez que gelos tomaren o fallaren dentro de la cibdad o en panes o en huertos o en vyñas o cercanos al muro de partes de dentro de la cibdad e de fuera de la barbacana, porque fazen daño hoçando con los rostros, un $\mathrm{mr}$. para los nuestros mayordomos". ${ }^{(89)}$ Incluso las ordenanzas permitían a los alguaciles matar aquéllos cerdos que encontrasen vagando libremente por las calles; en 1493, el cabildo dió un plazo de seis días para encerrar en las casas a todos los puercos que andaban sueltos "si no que pasado el término, los puercos que anduvieren por las plaças e calles, que el alguazil mayor e su lugarteniente los puedan alançear"; y la misma disposición vuelve a repetirse en el año 1500, prueba evidente de que esos animales seguían circulando por medio de la ciudad: "que se pregone que no anden los puercos sueltos por las calles so pena quel que anduviere suelto que lo maten e muerto sea para su dueño, e esto que no se entienda a los puercos que vienen a vender a esta cibdad ... e que en el campo de la uerdad no anden puercos so pena si fueren de veynte puercos abajo de trezientos mrs. e ende arriba seysçientos mrs. por cada vez que entraren". ${ }^{(90)}$

Su presencia en el interior de mesones y posadas era también motivo de conflictos, como testimonia un capítulo de las ordenanzas de 1435 por el que se prohibía a los mesoneros tener puercos o gallinas en sus posadas, debido a que comían la cebada de los caballos y mulas de quienes allí se hospedaban: "Por quanto nos fue dicho que los mesoneros e mesoneras desta cibdad crian e tienen puercos e puercas e gallynas que comen la cebada de las vestias de los que vienen a posar en los mesones, de lo qual se les sygue daño a los camineros, por ende mandamos e 
tenemos por bien que ningund mesonero desta dicha cibdad nin de su término que no sean osados de criar ni tener ningunos puercos e puercas ni cochinos ni gallynas en los mesones que tovieren, e que tengan los pesebres de los dichos mesones bien fechos e bien adobados e bien altos, porque las bestias que traxeren los que vinieren a los dichos mesones a posar puedan comer la paja e cebada que les fuere echada por los dueños dellas syn ningund contrario". Y esta misma prohibición vuelve a aparecer a fines de siglo referida concretamente a los mesones del puente de Alcolea donde "los mesoneros tienen puercos que comen la cebada de las bestias de los caminantes e mandaron que no los tengan so pena que gelos maten ${ }^{\text {rt }}{ }^{(91)}$ lo que demuestra, una vez más, que se trataba de una costumbre muy arraigada a pesar de las reiteradas prohibiciones que se hacen extensivas a otras ciudades de la época, como es el caso de Carmona, cuyas ordenanzas disponían "que ningún mesonero sea osado de traer gallinas ni aves por sus casas y mesones, ni puercos chicos ni grandes, salvo que los tengan en sus corrales apartados y con sus cerraduras y los puercos los tengan atados, de manera que no se suelten y fuera de las caballerizas". ${ }^{(92)}$

Otro animal muy común era la vaca y, sobre todo, los caballos, mulas y asnos que, usados habitualmente para el transporte, se encontraban en un gran número de viviendas y eran los principales productores de estiércol y quienes más contribuían, por tanto, a la falta de higiene en las calles. Los establos de estos animales solían ser habitaciones de casas particulares en pleno corazón de la ciudad, pues lo mismo los encontramos en residencias familiares que en tiendas o lugares de uso más o menos público. Por ejemplo, el aljabibe Gonzalo de Eslava arrendó al trapero Alfonso Martínez una tienda con dos puertas en la calle de los Marmolejos, autorizándole a tener "su mula en el establo de la dicha tyenda libremente". ${ }^{(93)}$ En ese sentido, las ordenanzas de alarifes disponían que cuando se construyese un establo no se pudiera hacer lindante con el tabique del dormitorio de otra casa, y si se hacían junto a una pared ajena el dueño tenía la obligación de colocar los pesebres junto a ella, de forma que las patas de los animales provocasen siempre el daño - los ruidos en su propia pared; cuando se trataba de arrendar la casa a un nuevo inquilino, el anterior debía arreglar la parte de suelo que hubiera sido dañada por los animales y dejar la casa libre de estiércol y de basura. $^{(94)}$

Otro animal cuya presencia en la ciudad estaba muy generalizada y resultaba igualmente perjudicial para la higiene de la misma era la paloma. Las ordenanzas de alarifes señalan el daño que éstas ocasionaban sobre los tejados, cámaras y corrales de las viviendas, hasta tal punto que prohibían la construcción de palomares dentro de la ciudad si no se contaba previamente con la licencia municipal "porque fazen gran daño las palomas en los tejados e si algund ome lo fiziere dentro con licençia de la cibdad no faga el anden de las palomas contra tejados agenos porque las palomas fazen gran ruido e ponen contyenda entre los 
omes si no fuera el palomar más antiguo que los tejados de sus vezinos". Y obligaban a los dueños de las palomas a pagar todos aquéllos daños que las mismas produjeran en los tejados ajenos. ${ }^{(95)}$ Pese a estas disposiciones, sabemos que existían abundantes palomas en el interior de la ciudad aunque, de vez en cuando, el cabildo recordara a los vecinos la obligatoriedad de cumplir unas ordenanzas que dudamos fueran obedecidas o aplicadas en la práctica. ${ }^{(96)}$

\section{Acción contaminante de las aguas}

Lógicamente, no eran sólo los residuos orgánicos los responsables de la suciedad en las ciudades bajomedievales. Uno de los elementos que más contribuía a la falta de higiene y a la distribución de las inmundicias por sus calles era el agua que circulaba por ellas, tanto en forma de arroyos, como de caños o canales, mediante los que se evacuaban las aguas "luvias" (o de lluvia) y las residuales.

En el siglo XV eran muy numerosos, mucho más que en la actualidad, los arroyos que seguían el tramo final de su curso por el interior de Córdoba, los cuales, aparte de transportar hacia el Guadalquivir las aguas procedentes de veneros o manantiales situados en la sierra, servían también como auténticos colectores naturales que llevaban hacia el río las aguas usadas por la población. Esta es una característica común a la mayoría de las ciudades de la época y, en tal sentido, cita Leguay el caso del arroyo de Menilmontant al que define como verdadera "cloaca natural" de algunos barrios de París. ${ }^{(97)}$ A ellos iban a parar buena parte de las llamadas "aguas continuas", es decir, aquéllas usadas en el trato de la casa y su contaminación se veía agravada porque también eran arrojadas basuras, desechos humanos e industriales, todo lo cual acumulaba una gran suciedad producto de la cual nacían malos olores e infecciones.

Debido a la propia densidad de los materiales que transportaban o a hechos fortuitos como podían ser la caída de piedras en su cauce o la obstaculización del mismo por otros elementos, la formación de azolves resultaba bastante frecuente en tales arroyos y ello presentaba como principal problema el de ocasionar inundaciones en zonas más o menos concretas de la ciudad; el mismo problema se detecta en Burgos con inundaciones frecuentes y continuos intentos de limpieza de dichas obstrucciones por parte del cabildo. ${ }^{(98)}$ Los lodos o basuras que obstruían los cauces resultaban especialmente comunes cuando se producían crecidas en los ríos y arroyos a causa de la abundancia de precipitaciones; por ejemplo, en los contratos de arrendamiento de aceñas y batanes conservados entre los protocolos cordobeses del siglo XV es usual ver aparecer una claúsula según la cual, si sobrevenía una crecida del río, el arrendatario quedaba obligado a reparar los posibles daños y desperfectos que el agua hubiese ocasionado en el interior del molino y, entre ellos, a 
retirar de las bóvedas (o conductos por los que se dejaba pasar el agua para mover los rodeznos) los azolves acumulados. ${ }^{(99)}$ Otros se formaban en diversas partes de la ciudad, como evidencian las actas capitulares de 1493 al indicar "en lo de la petiçión de los vezinos e clérigos de San Pedro que dieron sobre el azolue que se faze de lodo cerca de San Pedro, mandaron que Juan de Molina, jurado de dicha collaçión, e Alonso de los Ríos fagan repartimiento entre los vezinos que lo deben pagar e el dinero lo pongan en poder de una persona buena de la dicha collaçión".(100)

La única solución para impedir la formación de azolves en los arroyos que atravesaban la ciudad y evitar, así, las inundaciones que éstos podían originar, era efectuar una limpieza periódica de su cauce. No cabe duda de que la misma debió llevarse a cabo en todos los arroyos existentes en la época (arroyo de las Piedras, de las Moras, de la Fuensanta, de la Palma, del Moro, etc.), pero el que con mayor frecuencia aparece reflejado en las actas capitulares es el llamado arroyo de San Lorenzo, del cual se realizó una limpieza a fines del año 1498 y varias más durante el año 1499; concretamente, en octubre de este año "mandaron al jurado Juan de Cárdenas que faga tirar unas piedras que están caydas en el arroyo que dizen de San Lorenço, entre las puertas de Andújar y de Baeça, de una torre que se cayó para que vaya el agua del dicho arroyo desenbargadamente". (101) Tales limpiezas solían ser hechas por uno o varios particulares contratados por el cabildo ${ }^{(102)}$ y abonadas mediante reparto entre los vecinos del barrio donde fuera realizada la limpieza, como ocurrió en 1498 cuando el cabildo ordenó "que el jurado Luys de Valençuela con los alarifes tome seys vezinos de los más ricos y de medianas faziendas y de menores para facer repartimiento de los dieciseys mil mrs. por los que se remató la linpieça del arroyo de San Lorenço segund las condiçiones". ${ }^{(103)}$ Al margen de estas actuaciones puntuales, eran los mayordomos los encargados de mantener limpios los arroyos, cosa que seguramente llevarían a cabo con el mismo grado de eficacia que mostraban en la limpieza de las calles, a juzgar por las reiteradas ordenanzas dictadas en tal sentido como la dirigida al mayordomo Sancho Montesino en 1499 para que "con los mayordomos que fueren daquí adelante tengan cargo de linpiar e tener linpio el arroyo de San Lorenço con çiertos capytulos que la cibdad mandó fazer sobre ello". (104)

Además de las inundaciones provocadas por atranques en los arroyos, no cabe duda de que las más importantes y perjudiciales para la ciudad eran las ocasionadas por los desbordamientos periódicos del Guadalquivir. Este tema, que ha sido bien estudiado para el caso de Sevilla, ${ }^{(105)}$ es mucho peor conocido para la ciudad de Córdoba, a pesar de que contamos con numerosos testimonios sobre sus avenidas en tiempos de la dominación musulmana y en el curso de los siglos XV, XVI y XVII. ${ }^{(106)}$ La más famosa y mejor documentada de época medieval, fechada en 1481, fue vista así por un escribano que dejó entre los protocolos de Córdoba la siguiente noticia: "En sábado, nueue días del mes de dizienbre 
de Ixxxi porque no llouía subió el pan a ochenta mrs. la libra e aún más, e dende en adelante llouió diez e syete dias de enero deste año de ochenta e uno que no cesó de día ni de noche, que poco que mucho, e cresçió el río fasta llegar el agua por ençima de las dos gradas de Sant Nicolás del Axerquía e andauan los varcos por la calle que va de la cortidoría a la putería, e entró el agua por la puerta Martos aunque estaua çerrada fasta meytad de la plaça de las syete menas fasta una cruz que está fecha en el tynte de remonyr, e cubrió las açeñas e lleuó el tejado de las açeñas de Martos, e derrocó la casa de la beata e de Martín Valiente, e amarraron los pinos con maromas porque llegaua a ellos el agua, e yva el río fasta la fuente santa e entró dentro en la yglesia e derrocó todas las casas que estauan fechas en la huerta de Ferrando de Fyguero, e llegó fasta que se cubrieron dos o tres arcos de la puente e no podían pasar a los corrales syn barco ni a la Calahorra. E este escriuano público cuya es esta nota e Diego Sánches, astero, e muchos onbres y mugeres vimos nadar un onbre desnudo en cueros syn ninguna cosa, entre la pontesilla de la fuente santa e la mesma fuente santa, en el agua que llegaua y del río e lo vy çanbollir tres e quatro vezes". ${ }^{(107)}$ Es fácil imaginar los perjuicios que este tipo de riadas ocasionarían sobre los edificios de la ciudad y el estado en que las calles quedarían tras la retirada de las aguas.

Por otra parte, las malas condiciones urbanísticas de muchas ciudades, la existencia de barrios más bajos que el resto de la población o la falta de nivelación del terreno, eran circunstancias que contribuian a favorecer la aparición de encharcamientos y lagunas, los cuales podían ser ocasionales (en el caso de desbordamientos de arroyos o roturas de conductos de agua) o permanentes. Es famoso el caso de las lagunas de Feria y de la Pajería en Sevilla ${ }^{(108)}$ y en Córdoba conocemos la existencia de una situada en los actuales Jardines de Agricultura y otra en el sector urbano llamado "La Rehoyada", pero no han quedado más testimonios sobre aguas estancadas que tan nocivas resultaban para la salud. Esporádicamente, aparecen menciones acerca de acumulación de agua en determinadas zonas urbanas, que el cabildo se encargaba de hacer desaparecer, como en 1497 cuando se ordena "que los alarifes vayan a ver una mina de agua que se ha abierto en la puerta de Plasençia" o en 1499 cuando "se diputa para ver el agravio del arroyo que ua de la puerta de Seuilla al corregidor Luis de Angulo, Sancho Carrillo, Cristoual de Mesa e Alfonso de los Ríos, para que vayan allí con los alarifes e otros maestros para que se dé la orden que se deue dar como se quite dallí aque! agua". (109)

Otras veces tales acumulaciones de agua eran debidas a las que caían en época de lluvia. Como hemos indicado, muchos de los arroyos eran auténticos colectores que hacían las veces de alcantarillado para transportar el agua caída. Hasta principios del actual siglo se conservaron en Córdoba algunos arroyos al descubierto que, más o menos canalizados, servían para dicho cometido, como era el caso del llamado arroyo de San Andrés que bajaba el agua desde la plaza de Colón y a 
través de la Fuenseca hasta San Lorenzo, para convertirse allí en arroyo de San Lorenzo y llegar con ese nombre hasta el Guadalquivir. Aparte de ellos, las conducciones que evacuaban el agua de lluvia iban en su mayor parte descubiertas por encima del suelo y pocos tramos viarios de la Córdoba del siglo XV contaban con un sistema de alcantarillado subterráneo. La Córdoba árabe poseía una completa red de alcantarillado urbano del llamado sistema perpendicular, formado por una serie de amplios colectores que bajaban desde la parte alta de la ciudad hacia el río por el subsuelo de las calles principales, recogiendo en su trayecto las aguas de las alcantarillas secundarias. Francisco Azorín estudió parte de dicha red a principios de siglo, ofreciendo un croquis de su sector principal, el que atravesaba la Medina, que estaba formado por tres grandes ramales, uno que bajaba desde las Tendillas por Blanco Belmonte y Jesus María y salía al río siguiendo el muro oriental de la Mezquita; otro que partía de la zona de San Nicolás de la Villa, bajaba por Buen Pastor y Deanes y se dirigía al río junto al muro occidental de la Mezquita; y un tercero que recogía las aguas de la Judería y por las calles Judíos y Tomás Conde las llevaba al río atravesando el Alcázar. ${ }^{(110)}$ Aunque el sistema instalado por los musulmanes pervivió durante algunos siglos después de la conquista, al menos en esta zona tan notable de la ciudad, en los barrios orientales de la misma, ubicados fuera de la antigua Medina árabe --zona conocida durante la Baja Edad Media como Axerquía (de asSharqiya, oriental)--, la red de alcantarillado árabe de naturaleza secundaria debió de perderse, pues las ordenanzas y documentos de los siglos XIV y XV solo hablan de canales al descubierto o caños cubiertos de pequeño tamaño cercanos a la superficie; el Caño de Vecenguerra y el Caño Quebrado son buenos ejemplos de este tipo de conducciones.

La recogida del agua de lluvia en el interior de cada edificio se realizaba mediante caños (de plomo o barro) cuya colocación era regulada por las ordenanzas municipales a fin de evitar los daños que su caída sobre tejados o paredes ajenos, o su discurrir junto a paredes o cimientos, podían ocasionar. ${ }^{(111)}$

Las aguas residuales resultaban más nocivas para la higiene de la población que las anteriores. El principal problema era el mal olor, de manera que se recomendaba construir los caños encargados de evacuarlas por debajo de tierra: "qualquier casa que reçibiere agua de otra casa por caño descubierto por çima del suelo no es razón que reçiba otras aguas sino las luuias, porque las aguas continuas van turuias del trato de la casa e de muchas maneras ... e si las continuas oviere de reçebir, reçíbalas por caño cubierto debajo de tierra pues a cabsa de los fedores de las aguas ay muchas contyendas entre los vezinos". ${ }^{(12)}$ Y aún así, el mal olor o la contaminación que llevaban unidos era causa frecuente de disputas entre los habitantes de la ciudad, en las que el cabildo se veía obligado a intervenir ocasionalmente, como en 1499, cuando "en lo de la petiçión de los vezinos que moran junto con Santa Clara sobre los caños que salen del monasterio, cometióse a Martín Alfonso e a Sancho Carrillo 
para que lo vean e provean por manera que no reçiban agrauio los vezinos e el pueblo". (113)

Fundamentalmente las aguas residuales eran evacuadas a través de sumideros que debían ser construidos por los vecinos en el interior de sus propias viviendas según regulaban las ordenanzas de alarifes al disponer "que ningund ome faga sumidero en la calle del rey para echar agua de sus casas en él ... e si alguno quisiere fazer sumidero ... fágalo de la puerta adentro de su casa, so pena que los alarifes lo manden desbaratar, cerrar y sacar a pisón",(114) puesto que si querían hacerlo en ella debían contar con la licencia previa del cabildo. ${ }^{(15)}$ A pesar de las regulaciones efectuadas por éste, los sumideros y caños fueron causa frecuente de problemas entre vecinos dado que, a veces, se realizaban excesivamente próximos a paredes o pozos ajenos ${ }^{(16)}$ y debían limpiarse a costa de quienes los usaban, causas por las cuales se originaban múltiples debates. (117)

Al margen de sumideros y cañerías, las propias necesarias (nombre con el que en la época son designadas las letrinas) podían constituir un grave perjuicio para los vecinos si eran colocadas demasiado cerca de paredes o pozos o en lugares desde los que su olor supusiera una molestia, como manifiestan las ordenanzas de alarifes al prohibir hacerlas "junto con pared agena ni en tal lugar que agrauie de fedor a su vezino ni dañe pared ni poço de su vezino". ${ }^{(118)}$ Es de suponer que en muchas viviendas ni siquiera existirían necesarias, caso en el cual eran sustituidas por bacines cuyas aguas sucias solían ser arrojadas a la calle. Esta costumbre está documentada en diversas ciudades de la época; por ejemplo, en el Leicester del siglo XIV una ordenanza, fechada en 1335 , prohibía a cocineros y pescadores arrojar agua bajo pena de prisión, y las autoridades de Londres estaban muy irritadas por este tipo de ofensa cuando en 1414 ordenaron a sus oficiales tomar severas medidas contra quienes incurriesen en ella. ${ }^{(119)}$

Este mal hábito aparece documentado con frecuencia en la ciudad de Córdoba, puesto que conocemos ordenanzas destinadas a combatirlo; de 1435 son las que multan con 12 mrs. a "quien echare hezes o ceruada en la calle o otro lixo" y de 1497 las que disponían "que ningund vezino de la cibdad sea osado de echar detrito de la baçinada en las calles de la cibdad so pena de las ordenanças della e demás un real de plata castellano para la obra de la cárçel, e que esta pena e ordenança sean obligados los mayordomos a executarla". ${ }^{(20)}$ Aguas sucias procedentes de otro tipo de actividades podían ser también arrojadas a la calle cuando las ordenanzas insisten en que "ningund onbre ni muger no eche en la calle agua de azeyte que sea fecho a pie, nin agua primera ni otra que fuera del remojo del pescado". (121)

$Y$ no solo eran las calles las que se veían amenazadas por las aguas sucias resultantes de las labores domésticas. También las fuentes y pilares, tan abundantes en la época, podían sufrir sus consecuencias. Un testimonio muy expresivo de los perjuicios que en las mismas podían 
ocasionar los particulares es el proporcionado por las ordenanzas de Carmona cuando prohiben "que ninguno eche en la fuente piedra, tierra, paja, cosa hedionda viva o muerta (el que así lo echare sea traído a vergüenza de esta villa y esté en la picota cinco horas), ni se laven las manos, la cara ni la cabeza, ni paño ni lienzo ni otra cosa alguna, ni se saque agua de la fuente con caldera ni vasija sucia, ni entren dentro de la fuente a sacar agua ni a bañarse, y que ningún azacán lleve entre los cántaros banasta, ni cueros, ni pellejos de aceite, ni otra cosa sucia". ${ }^{(22)}$ Disposiciones similares a las que aparecen en ordenanzas de Guadalajara del siglo XIV y de Cañete de las Torres del siglo XVI. ${ }^{(123)}$

$Y$, cómo no, las acequias y canales que discurrían por el interior de las ciudades también sufrieron los perjuicios del vertido en ellas de sustancias contaminantes. Muchos de estos residuos procedían de las actividades industriales de la época (lavado de lanas, curtido de pieles, tinte de paños, etc.). ${ }^{(124)}$ pero otros eran el resultado de las labores domésticas llevadas a cabo por los contemporáneos. Las ordenanzas de Tobarra disponen que "ninguno sea osado de lavar tripas, carne, tocino ni cecinas en las acequias madres [...] ni capullos ni gusanos de seda en ninguna de las acequias desta villa [...] e que ninguna mugeres ni mozas no sean osadas de lavar trapos ni cosas del olmillo arriba viniendo el agua abajo [...] ni puedan lavar en los molinos ni en la tegera de la acequia madre, ni curen lienzos, salvo que puedan lavar en tornajo con que lo tengan apartado de la acequia diez pasadas de manera que el agua que lavaren no vuelva a la dicha acequia madre". ${ }^{(125)}$

En suma, un panorama bastante negativo para el mantenimiento de las condiciones de higiene y salubridad en el interior de la ciudad se presenta a nuestros ojos. En Córdoba, como en los restantes centros urbanos de la época, las autoridades municipales apenas pudieron hacer frente con éxito a los problemas planteados en esta materia y es precisamente gracias a ese fracaso, es decir, a las reiteradas disposiciones que los capitulares dictaron en ese sentido y que nunca alcanzaron cumplimiento, por lo que hoy podemos conocer mejor los principales problemas que en aquel ámbito existieron. 


\section{NOTAS}

1. G. Salusbury-Jones, Street Life in Medieval England, Londres, 1975, p. 55;

V. Franchetti, Historia del Urbanismo. Siglos XIV y XV, Madrid, 1984, p. 124.

2. I. Falcón, Zaragoza en el siglo XV. Morfología urbana, huertas y término municipal, Zaragoza, 1981, p. 75; J. Valdeón, C. Estepa, T. Ruiz, J. Bonachia e H. Casado, Burgos en la Edad Media, Valladolid, 1984, p. 236; H.V. Navarro Pascual, Tobarra, en el tránsito de la Edad Media a la Moderna a través de sus ordenanzas, Memoria de Licenciatura inédita, Facultad de Letras de Cáceres, 1989, f. 97.

3. Ordenanzas de alarifes 1493, Archivo Municipal de Córdoba [AMC], Libro de Ordenanzas $1^{\circ}$ [LO], cap. 116, f. 154v y ordenanza de los que embargaren las calles, AMC, LO. 1ㅇ, f. 232v. De contenido similar a las emitidas en la villa de Tobarra, donde se manda que "qualquiera que embargare con leña, basura, tinajas, madera $u$ otras cosas las calles, que lo quite e haya quitado el segundo día so pena de cinco mrs." (H.V. Navarro, op. cit., f. 14).

4. Ordenanzas de alarifes, AMC, LO. 1ํ, cap. 115, f. 154v; 1493.04.19, AMC, Libro de Actas Capitulares [LAC] 2o, Sección 19, Serie 1 y 1495.01.28, AMC, LAC. 3ํㅗ Secc. 19, Ser. 1.

5. A.J. Albardonedo, "Aspectos urbanos de Sevilla durante el reinado de Felipe III", Archivo Hispalense, 216, 1988, p. 131.

6. I. Falcón, op. cit., pp. 76-77 y nota 328; ordenanzas de alarifes, AMC, LO. 1, cap. 34, f. 140r.

7. M. Asenjo, Segovia. La ciudad y su tierra a fines del Medievo, Segovia, 1986, p. 58; 1493.04.15 y 1493.04.27, AMC, LAC. $2^{\circ}$, Secc. 19 , Ser. 1.

8. 1496.11.20, AMC, LAC. $4^{\circ}$, Secc. 19, Ser. 2 y 1498.01.10, AMC, LAC. $6^{\circ}$, Secc. 19, Ser. 2. Pedro López, mesonero, vecino de la collación de San Nicolás de la Axerquía, arrienda a Bartolomé Ruiz, herrador, vecino de la de Santa María, un poyo que está en la puerta de su mesón, cerca de la plaza del Potro, "donde pueda meter e sacar su ferraje e arca e usar de su ofiçio, tanto en la puerta e calle del mesón como dentro dél" (1498.01.09, Archivo Histórico Provincial de Córdoba [AHPC], Oficio 14 - Legajo 34, Cuaderno 3, folio 23v).

9. I. Falcón, op. cit., p. 74 y ordenanzas de alarifes, AMC, LO. $1^{\circ}$, caps. 23,24 y 104 , ff. 138 r y 152 r.

10. M. Asenjo, op. cit., p. 61; E. C. de Santos, La Historia Medieval de Plasencia y su entorno geohistórico: la sierra de Béjar y la sierra de Gredos, Cáceres, 1986 , p. 139.

11. 1499.06.03 y 1499.06.07, AMC, LAC. $7^{\circ}$, Secc. 19 , Ser. 2.

12. Ordenanzas de alarifes, AMC, LO. 1, cap. 25, f. 138v; A. Collantes, Sevilla en la Baja Edad Media. La ciudad y sus hombres, Sevilla, 1977, p. 76; J. Valdeón y otros, op. cit,, p. 230; I. Falcón, op. cit., p. 78. 
13. J. Miley, La vie parisienne á travers les âges, París, 1965.

14. J. P. Leguay, La rue au Moyen Age, Rennes, 1984, p. 127.

15. J. Favreau, "Les rues de Poitiers au Moyen Age", Bulletim de la Societé d'Antiquaires de l'Ouest, 15, 1979, p. 231; ordenanzas de alarifes, AMC, LO. $1^{\circ}$, ff. $159 \mathrm{v}-160 \mathrm{r}$.

16. J. Valdeón y otros, op. cit., p. 230; 1496.11.30, Archivo General de Simancas [AGS], Registro General del Sello [RGS], f. 269; A. Collantes, op. cit., p. 76.

17. Pregones para que los curtidores no cuelguen cueros en los adarves, AMC, LO. $1^{\circ}$, f. 232; 1493.05.13, AMC, LAC. $2^{\circ}$, Secc. 19, Ser. 1; ordenanzas de alarifes, AMC, LO. 1, ff. $151 \mathrm{v}$ y $159 \mathrm{v}$.

18. J. P. Leguay, op. cit., p. 130; 1496.02.03, AMC, LAC. 4º, Secc. 19, Ser. 2.

19. J.P. Leguay, op. cit., pp. 64-65.

20. M. Asenjo, op. cit, p. 59; M.I. Falcón, op. cit., p. 75 (sin que pudiera remediar este problema el recurso de cubrir el terreno con paja o juncos); M. Barceló, "La ciudad de Mallorca en el último cuarto del siglo XV: parroquias y red viaria", La Ciudad Hispánica durante los siglos XIII al XVI, Madrid, 1985, II, p. 1328. 21. M. C. Carlé, La sociedad hispano-medieval. La ciudad, Buenos Aires, 1984, p. 41 ; A. Collantes, op. cit., p. 82.

22. V. Franchetti, op. cit., p. 129.

23. P. Lavedan, J. Hugueney, L'Urbanisme au Moyen Age, Ginebra, 1974, p. 146; J. Favreau, op. cit., p. 225.

24. María Barceló señala que en Mallorca el empedrado solo se generalizó a partir de 1777, siendo utilizado hasta entonces con carácter general el piso de terrisco. M. Barceló, op. cit., p. 1328.

25. M. Asenjo, op. cit., p. 59; M. Montero, El Madrid medieval, Madrid, 1987, p. 287.

26. G. Salusbury-Jones, op. cit., p. 13.

27. 1493.03.04, AMC, LAC. $2^{\circ}$, Secc. 19, Ser. 1.

28. 1479.09.10, AMC, LAC. 1ํ, Secc. 19, Ser. 1.

29. Ordenanza de los que hacen zahurdas, AMC, LO. 1ํ, f. 232v; ordenanzas de alarifes 1497, AMC, LO. 1ㅜ, cap. 27, f. 138v.

30. 1496.02.03, AMC, LAC. 4으, Secc. 19, Ser. 2; 1499.01 .02 y 1499.03.18, AMC, LAC. $7^{\circ}$, Secc. 19, Ser. 2.

31. 1493.03.22, AMC, LAC. $2^{\circ}$, Secc. 19 , Ser. 1 y ordenanzas de alarifes 1497 , AMC, LO. $1^{\circ}$, f. 149 r.

32. 1496.07.14, AGS, RGS, f. 18; M. Montero, op. cit, p. 287; E. C. de Santos, op. cit., p. 139; J. Valdeón y otros, op. cit., p. 236; y P. López Alsina, Introducción al fenómeno urbano medieval gallego a través de tres ejemplos: Mondoñedo, Vivero y Ribadeo, Santiago, 1976, p. 56. 
33. A. Collantes, op. cit., p. 83.

34. 1493.04.15, AMC, LAC. $2^{\circ}$, Secc. 19, Ser. 1.

35. . Fechada en 1502.12.23, Ordenanzas para el buen régimen y gobierno de la muy noble, leal e imperial ciudad de Toledo, Toledo, 1858, Tit. 66, p. 111; M. Asenjo, op. cit., p. 60.

36. 1498.10.19, AMC, LAC. 6으, Secc. 19, Ser. 2; 1493.04.15, AMC, LAC. $2^{\circ}$, Secc. 19, Ser. 1 ("Si no las derribaren, que pague cada uno por su poyo o calçada dosçientos mrs... los quales serán para el enpedrar de las calles donde estouieren los dichos poyos e calçadas"); 1493.02.11, AMC, LAC. $2^{\circ}$, Secc. 19, Ser. 1 y 1497.01.30, AMC, LAC. 4ㅇ, Secc. 19, Ser. 2 ("Que se aplique la pena del xabonero a çiertas obras públicas que son en enpedrar la calle de San Juan y la Reja").

37. J. P. Leguay, op. cit., p. 71.

38. 1498.07.02, AMC, LAC. $6^{\circ}$, Secc. 19, Ser. $2 ; 1499.04 .24$, AMC, LAC. $7^{\circ}$, Secc. 19, Ser. 2.

39. 1493.02.15, AMC, LAC. $2^{\mathrm{o}}$, Secc. 19, Ser. 1.

40. J. Favreau, op. cit., p. 225; J. P. Leguay, op. cit., p. 71; E. L. Sabine, "City Cleaning in Medieval London", Speculum, 12, 1937, p. 22; A. Collantes, op. cit., p. 83.

41. 1493.07.17 y 1493.12.23, AMC, LAC. 2ㅇ, Secc. 19, Ser. 1.

42. Como A.J. Albardonedo afirma para el caso de Sevilla --y ello es perfectamente aplicable a la mayor parte de los centros urbanos de época medieval y moderna--, sólo a fines del siglo XVI y durante el XVII comienzan a pavimentarse las calles alejadas del centro urbano (A.J. Albardonedo, A.J., op. cit., p. 128).

43. J. M. Escobar, Córdoba en la Baja Edad Media, Córdoba, 1989, p. 97.

44. Noticias citadas en 1493.02.05, AMC, LAC. 2, Secc. 19, Ser. 1; 1493.03.22, AMC, LAC. $2^{\circ}$, Secc. 19, Ser.1; 1499.04.24 y 1499.07.17, AMC, LAC. $7^{\circ}$, Secc. 19, Ser. 2; 1493.04.24, AMC, LAC. 2ㅇ, Secc. 19, Ser. 1; 1495.07.31, AMC, LAC. $3^{\circ}$, Secc. 19, Ser. 1; 1497.07.05, AMC, LAC. 5으, Secc. 19, Ser. 2; 1496.06.10, AMC, LAC. 4ㅇ, Secc. 19, Ser. 2; 1493.11.06, AMC, LAC. 2, Secc. 19, Ser. 1; 1498.07.02, AMC, LAC. 5ㅇ, SecC. 19, Ser. 2.

45. 1493.04.15 y 1493.04.27, AMC, LAC. $2^{\circ}$, Secc. 19, Ser. 1.

46. A. Collantes, op. cit., pp. 82-83; Rodrigo Alonso, albañil, se compromete con Gonzalo Vázquez, escribano del cabildo, "a poner e asentar e dar asentados a su costa e misyón veynte e tres mill ladrillos en la calle de Chapineros e Cordoneros e cal de Francos" (1498.06.25, Archivo de Protocolos de Sevilla [APS], Oficio 9 . Legajo 30, f. 193v). En otro caso, Nicolás Pérez acuerda suministrar al albañil Alfonso Martínez los ladrillos que necesite cada día para solar las calles de Sevilla, acarreándolos desde la rivera hasta el sitio que le señalare, por precio de $45 \mathrm{mrs}$. el millar de ladrillo (1499.04.02, APS, 9.32, f. $139 \mathrm{v}$. Citados ambos por J. Bono, Los protocolos sevillanos en la época del 
Descubrimiento, Sevilla, 1986, pp. 218 y 223). Conocemos igualmente el caso de doña Guiomar Manuel que, en 1418, "dió un grueso socorro a la ciudad, en beneficio de lo público, para que ladrillasen sus calles" (M. A. Ladero, Historia de Sevilla. La ciudad medieval, Sevilla, 1977, p. 51).

47. J. Valdeón, op. cit., p. 235; M. Asenjo, op. cit., p. 60; "Que los marmolejos se enpedren e pongan sillares de canto e enmedio guijas menudas en cal e arena" (1493.11.13, AMC, LAC. $2^{\circ}$, Secc. 19, Ser. 1). El uso de la cal en esta actividad queda reflejado en un protocolo por el que Pedro Fernández, calero, vende al albañil Juan Ruiz dos mil fanegas de cal "entregada en esta cibdad en las casas de su morada desde el día que començare a fazer la obra del empedramiento que está a su cargo hasta darla acabada" (1493.05.14, AHPC, 14-28, 6, 7v).

48. 1499.04.12, AMC, LAC. $7^{\circ}$, Secc. 19, Ser. 2.

49. J. Favreau, op. cit., pp. 225-227 y J. P. Leguay, op. cit., p. 74.

50. J. Valdeón, op. cit., p. 236; ordenanzas de alarifes 1497, AMC, LO. 1ํ, f. 157r-v; 1493.07.29, AMC, LAC. $2^{\circ}$, Secc. 19, Ser. 1.

51. 1493.10.07, AMC, LAC. $2^{\circ}$, Secc. 19, Ser. 1; 1498.11.23, AMC, LAC. $6^{\circ}$, Secc. 19, Ser. 2.

52. 1493.10.02, AMC, LAC. $2^{\circ}$, Secc. 19, Ser. 1.

53. Como prueba la carta dirigida por Juan de la Sal a un miembro del Consejo de Castilla en junio de 1624, donde le decía cómo "las calles deste lugar son tan angostas que en muchas no pueden pasar coches... el terreno por las muchas humedades es movedizo y no pudiendo los coches extenderse es fuerza que vayan todos en unas mismas rodadas... sin que haya empedrado que haga resistencia al cabo de quince o veinte días... porque el gasto excesivo de la ciudad en empedrar las calles es totalmente inútil" (A. J. Albardonedo, op. cit., pp. 127-128).

54. E. C. de Santos, op. cit., p. 139.

55. Ordenanzas de alarifes 1497, AMC, LO. $1^{\circ}$, cap. 43, f. 142v.

56. A. Collantes, op. cit., p. 102; A. Higounet-Nadal, "Hygiène, Salubrité, Pollutions au Moyen Age. L'exemple de Périgueux", Annales de Démographie Historique, 1975, pp. 81-92.

57. Jean Pierre Leguay, op. cit., p. 61. Esto es así hasta tal punto que Richard Trexler ha podido afirmar que buena parte de la legislación sanitaria de la Europa medieval tras la Peste Negra estuvo determinada por la creencia de que ciertos elementos animales y humanos, tales como excrementos y basuras, corrompían el aire e infectaban a la población (R. Trexler, "Measures against Water Pollution in Fifteenth-Century Florence", Viator, 5, 1974, p. 456).

58. E. L. Sabine, op. cit., p. 19.

59. H. V. Navarro Pascual, op. cit., que recoge disposiciones emitidas entre los años 1470 y 1560; M. Concepción Quintanilla, "Ordenanzas municipales de Cañete de las Torres (Córdoba) 1520-1532", Historia. Instituciones. Documentos, 2, 1975 . Tit. 4 , cap. 97 , f. $17 \mathrm{v}$. 
60. "Platicaron sobre el ofiçio del mayordomadgo de Córdoua que se iuntó a los corregidores para darlo a la cibdad para que los maiordomos tengan la cibdad linpia de todas las cosas, sobre lo qual acordaron de poner una buena persona que tenga el dicho ofiçio de mayordomía un año desde San Juan primero que verná, e el que lo tomare que se obligue a tener la cibdad lynpia e quando faltare que la cibdad la faga limpiar a su costa... e el que proveyere dicho ofiçio un año que no pueda ser proveido en él fasta que pasen otros dos años" (1499.06.03, AMC, LAC. $7^{\circ}$, Secc. 19, Ser. 2).

61. 1493.03.27, AMC, LAC. $2^{\circ}$, Secc. 19, Ser. 1 (el cargo parece haber conservado su papel en esta materia durante mucho tiempo, dado que en la Sevilla del siglo XVIl era también un alcalde mayor el encargado de supervisar la limpieza de las vías públicas y de todos los arrabales según pone de manifiesto A. J. Albardonedo, op. cit., p. 125; y 1493.06.14, AMC, LAC. 2, Secc. 19 , Ser. 1.

62. 1493.06.14, AMC, LAC. 2은, Secc. 19, Ser. 1; 1497.07.19, AMC, LAC. 5, Secc. 19, Ser. 2; y 1499.05.31, AMC, LAC. $7^{\circ}$, Secc. 19, Ser. 2.

63. 1493.02.25, AMC, LAC. $2^{\circ}$, Secc. 19, Ser. 1.

64. A. Collantes, op. cit., p. 104; J. Valdeón, op. cit., p. 239 y M. I. Falcón, op. cit., p. 78.

65. J. P. Leguay, op. cit., p. 86.

66. M. Asenjo, op. cit., p. 77; C. Mignot, "Le "municipio" de Guadalajara au XVème siècle, système administratif et économique 1341-1567", Anuario de Estudios Medievales, 14, 1984, p. 592.

67. A. J. Albardonedo, op. cit., p. 131.

68. 1493.05.08, AMC, LAC. $2^{\circ}$, Secc. 19, Ser. 1.

69. G. Salusbury-Jones, op. cit., p. 81; J. Favreau, op. cit., p. 234.

70. 1497.08.09, AMC, LAC. 5, Secc. 19, Ser. 2.

71. AMC, LAC. $2^{\circ}$, Secc. 19, Ser. 1; 1499.04.24, AMC, LAC. $7^{\circ}$, Secc. 19, Ser. 2.

72. 1493.01.28, AMC, LAC. $2^{\circ}$, Secc. 19, Ser. 1; y 1497.04.10, AMC, LAC. 5으, Secc. 19, Ser. 2. La práctica se mantuvo durante los siglos XVII y XVIII, pues en definitiva los usos y costumbres higiénicos medievales y renacentistas permanecerán casi inalterables hasta el siglo XIX, como pone de relieve A.J. Albardonedo, op. cit., pp. 125-126.

73. J. Valdeón y otros, op. cit, p. 239; M. Asenjo, op. cit, p. 76; E. C. de Santos, op. cit., p. 151; en la última de las localidades mencionadas las ordenanzas no dejan lugar a dudas al señalar los lugares autorizados para verter basura: "que ninguna persona sea osada de echar estiércol ni basura en las calles ni solares ni en toda la barbacana, ni heces ni orujo, salvo fuera del postigo ayuso del palo fuera de toda la villa [...] y que ninguno sea osado de echar estiércol ni otra basura alguna fuera de como dicen estos mojones que van por los vertares del portichuelo allende e enderredor del arrabal e corra- 
les desta dicha villa quinze pasadas allende de los mojones del dicho arrabal e corrales" (H. V. Navarro, op. cit., ff. 6 y 15).

74. 1493.05.08, AMC, LAC. $2^{\circ}$, Secc. 19, Ser. 2.

75. J.P. Leguay, op. cit, p. 56; A. Higounet-Nadal, op. cit., p. 84. Las ordenanzas de Cañete de las Torres indican que los almotacenes de la villa debian averiguar quien echaba perros o bestias muertos en las calles y, probado con el juramento de doce vecinos, cobrar al infractor una multa (C. Quintanilla, op. cit., Tit. 4, cap. 98, f. 17v).

76. De hecho, el propio término muladar proviene de muradal, palabra derivada de muro, debido a la frecuencia conque dichos depósitos se formaban junto a ellos ( $M$ a Jesus Suárez, La villa de Talavera y su tierra en la Edad Media, Toledo, 1982, p. 66).

77. Ordenanzas de 1435, AMC, LO. 1ำ f. 8v. Edit. M. González, Ordenanzas del concejo de Córdoba (1435), Historia. Instituciones. Documentos, 2, 1975, cap. 78, p. 227; ordenanzas de alarifes 1493, AMC, LO. 1ㅇ, cap. 62, f. 145 y cap. 107, f. 152v. Idéntica sanción económica aparece en Baeza por arrojar basura fuera de los muladares designados ( $\mathrm{M}^{\mathrm{a}}$ Josefa Parejo, Baeza y Ubeda en la Baja Edad Media, Granada, 1988, p. 47).

78. M. Asenjo, op. cit., p. 76.

79. 1498.09.24, AMC, LAC. $6^{\circ}$, Secc. 19, Ser. $2 ; 1499.04 .22$, AMC, LAC. $7^{\circ}$, Secc. 19, Ser. 2.

80. Ordenanzas de Guadalajara de 1384, citadas por F. Layna Serrano, Historia de Guadalajara y sus Mendozas en los siglos XV y XVI, Madrid, 1942, vol. $2^{\circ}$, p. 345.

81. "Que Gonçalo de Ayora e Fernando Cabrera vean una poca de tierra que está allende del muladar de la puerta del Rincón e si fallaren que se puede fazer una casa sin perjuyzio de la çibdad o de otra persona, den licencia a Gonçalo Martinez de Porcuna para facerla" (1479.03.30, AMC, LAC. 1ํ, Secc. 19, Ser. 1).

82. Curiosa ordenanza, que adopta una sabia solución para conseguir la limpieza del muladar a costa de los mismos vecinos que contribuían a formarlo (1497.06.05, y 1497.07.12, AMC, LAC. 5ํㅡ, Secc. 19, Ser. 2).

83. 1498.02.05, AMC, LAC. 6으, Secc. 19, Ser. 2.

84. Esta cláusula se incluye en un contrato mediante el cual Pedro Rodríguez, oropelero, y su mujer, vecinos de la collación de Santa María, arriendan unas casas-tienda del monasterio de Santa Clara en la plaza de la Carnicería (1491.08.23, Archivo Histórico Provincial de Córdoba [AHPC], [Oficio] 14 [Legajo] 26, [Cuaderno] 6, [folio] 45r); seis años antes, el monasterio había arrendado ya esa tienda al cabritero Antón de Alharón y a su mujer con las mismas condiciones (1485.11.09, AHPC, 14-5, 12, 9r).

85. B. A. Hanawalt, The Ties that Bound. Peasants Families in Medieval England, Londres, 1986, p. 41. 
86. Ordenanzas de 1435, AMC, LO. 1ํ, f. 3r; M. González, op. cit., cap. 6, p. 216.

87. J.P. Leguay, "La rue, element du paysage urbain et cadre de vie dans les villes du Royaume de France et des Grands Fiefs aux XIVe et XVe siècles", Le Paysage Urbain au Moyen Age, Lyon, 1981, p.39.

88. J. P. Leguay, La rue au Moyen Age, p. 59; B. A. Hanawalt, op. cit., pp. 37, 43 y 52 .

89. Ordenanzas de 1435, AMC, LO. 1º, f. 21r. M. González, op. cit., cap. 230, pp. 254-255.

90. 1493.11.20, AMC, LAC. $2^{\circ}$, SecC. 19, Ser. 1; 1500.01.24, AMC, LAC. $8^{\circ}$, Secc. 19 , Ser. 3.

91. Ordenanzas de 1435, AMC, LO. 1ํ, ff. 33v-34r; M. González, op. cit., cap. 335, p. 279; 1499.04.22, AMC, LAC. $7^{\circ}$, Secc. 19, Ser. 2.

92. M. González, Ordenanzas del concejo de Carmona, Sevilla, 1972. Título de los mesoneros y venteros, cap. $4^{\circ}$, p. 154.

93. 1495.04.02, AHPC, 14-31, 4, 11r.

94. Ordenanzas de alarifes, AMC, LO. 1으, cap. 126 , f. $156 \mathrm{v}$ y cap. 38 , f. 141 r. 95. Ibídem, cap. 19, f. $137 v$ y cap. 20 , f. 138 r.

96. Como en la sesión capitular en que se acordó pregonar "que se guarde la ordenança de los palomares" (1495.01.02, AMC, LAC. 3º Secc. 19, Ser. 1).

97. J.P. Leguay, La rue au Moyen Age, p. 84.

98. J. Valdeón, op. cit, p. 238.

99. 1476.08.27, AHPC, 14-9, 12, 103v; 1489.05.04, AHPC, 14-24, 5, 16v; 1495.07.03, AHPC, 14-31, 23, 23r; y otros muchos.

100. 1493.02.20, AMC, LAC. $2^{\circ}$, Secc. 19, Ser. 1.

101. 1498.10.19, AMC, LAC. $6^{\circ}$, Secc. 19 , Ser. $2 ; 1499.10 .30$, AMC, LAC. $7^{\circ}$, Secc. 19, Ser. 2.

102. "Que fagan ynformaçión sobre la linpieza del arroyo de San Lorenço, qué tyene reçebido el maestro que lo tomó a lympiar e qué está cogido e provean cómo se lympie según las condiçiones" (1499.06.03, AMC, LAC. 7ํㅜㄹ, Secc. 19, Ser. 2).

103. 1498.10.19, AMC, LAC. $6^{\circ}$, Secc. 19, Ser. 2.

104. 1499.10.25, AMC, LAC. $7^{\circ}$, Secc. 19, Ser. 2.

105. A. Collantes, Las crecidas del Guadalquivir en la Edad Media, Sevilla, 1974; F. Palomo, Historia crítica de las riadas o grandes avenidas del Guadalquivir en Sevilla desde su reconquista hasta nuestros dias, Sevilla, 1878, 2 vols.; M.A. Ladero Quesada, Historia de Sevilla II: la ciudad medieval, Sevilla, 1976, pp. 53- 54; y A.J. Albardonedo, op. cit., pp. 134-135. 
106. Como los proporcionados por Rafael Ramírez de Arellano en sus Paseos por Córdoba, Córdoba, 1983, pp. 489-490.

107. 1481.01.18, AHPC, 14-17, 3, 28r. Edit. E. Cabrera, R. Córdoba y J.L. del Pino, Textos histórico-geográficos de Córdoba y su provincia, Córdoba, 1988, p. 292.

108. A. Collantes, op. cit., p. 105.

109. 1497.04.26, AMC, LAC. 5ㅇ, SecC. 19, Ser. 2; 1499.03.20, AMC, LAC. $7^{\circ}$, Secc. 19, Ser. 2.

110. F. Azorín, "El alcantarillado árabe de Córdoba", Al-Mulk, 2, 1961-62, 192194.

111. "Que ningund ome pueda echar agua a casa agena ni por alto de tejado ni por caño" y "que los caños que se fazen dentro en casa no deuen ser fechos junto con pared agena e si los fizieren que los fagan tres pies desuiados de la pared del vezino e guarneçidos de cal e arena para la defensyón de todo el pudrimiento que del se espera" (Ordenanzas de alarifes, AMC, LO. 1º, caps. 129 y 91, ff. 156 v y $150 r)$.

112. Ibidem, cap. 51 , f. 144 r. Disposiciones como la anterior se repiten en las ordenanzas de muchas ciudades e incluso de pequeñas villas, caso de la cordobesa localidad de Cañete de las Torres, cuyos capítulos municipales indican que "qualquier vezino que dexare salir agua por el caño o caños de sus casas, paguen en pena por cada vez que salieren las dichas aguas $12 \mathrm{mrs}$., salvo sy fuere de la que llueve, esto por causa de los dichos caños se cohonden las calles desta villa" (M. C. Quintanilla, op. cit., Tit. 4, cap. 100, f. 18r).

113. 1499.07.17, AMC, LAC. $7^{\circ}$, Secc. 19, Ser. 2. Pero el problema, como viene siendo habitual para todo lo relacionado con el urbanismo, continuó existiendo largo tiempo. Todavía en 1620 el cabildo de Sevilla acordaba, "por lo mucho que importa que la ciudad esté limpia y que los empedrados se puedan conservar mejor, que las casas y conventos que tienen caños que salen a la calle, los cierren y quiten de manera que por ellos no puedan salir la dicha agua ni inmundicias" (A. J. Albardonedo, op. cit., p. 132).

114. Ordenanzas de alarifes, AMC, LO. 1ำ cap. 44, f. $143 r$.

115. Como la dada a Antonio de la Cuerda "para fazer un sumidero en una casa suya en la calle sin perjuyzio de la çibdad" (1493.10.30, AMC, LAC. $2^{\circ}$, Secc. 19, Ser. 1).

116. "Que ninguno pueda fazer sumidero en su casa çerca de poço ageno e si lo fiziere fágalo desuiado a trecho de una soga toledana, e si aún asy dañare el poço de su vezino, que los alarifes lo manden cerrar e sacar a pisón" (Ordenanzas de alarifes, AMC, LO. 1ㅜㅗ. cap. 86, f. 149r).

117. "Quando an contyenda sobre un sumidero, los alarifes deben juzgar que cada uno como uuiera pertenençia asy debe pechar en to que costare adobar el sumidero" (Ordenanza sobre los sumideros de las casas, AMC, LO. $1^{\circ}$, f. 233v); "licençia a Santa Clara para que un sumidero que está en el di- 
cho monasterio se abra e se lympie e lo bueluan a çerrar" (1499.05.22, AMC, LAC. $7^{\circ}$, Secc. 19, Ser. 2).

118. Ordenanzas de alarifes, AMC, LO. 19, cap. 92, f. 150r.

119. G. Salusbury-Jones, op. cit., pp. 73-74.

120. Ordenanzas de 1435, AMC, LO. 1ㅜ, f. 8r. M. González, op. cit., cap. 70, p. 226; 1497.06.26, AMC, LAC. 5으, Secc. 19, Ser. 2.

121. Ordenanzas de 1435, AMC, LO. 1, f. 8r. M. González, op. cit., cap. 72 , p. 226.

122. M. González, Ordenanzas del concejo de Carmona, Título de la fuente y azacanes, caps. 1ํ-으. pp. 133-134.

123. "Que qualquier hombre o muger que lavare dentro de la fuente ropa o qualquier cosa o en el pilar dentro o fuera hasta dos pasadas en derredor pague de multa cada vez diez mrs. para la labor de los caños" (Mandamientos de Guadalajara fechados en 1384 y citados por F. Layna, op. cit., p. 345); "qualquier personas que metieren en los pozos dulces del concejo desta villa cántaro de mosto o leche, pague en pena doze mrs. e esté doze días en la cárcel [...] o metieren en ellos caldera u otra vasija suzia" (M. C. Quintanilla, op. cit., Tit. 4, cap. 97, f. 17v).

124. R. Córdoba, "Los residuos industriales en las ciudades medievales y su tratamiento", La manufactura urbana i els menestrals, Palma de Mallorca, 1991, pp. 191-211.

125. H.V. Navarro, op. cit., ff. 91, 97, 114 y 127. 